\title{
Synthesis of the Saccharomicin Fucose-Aglycon Conjugate and Determination of Absolute Configuration
}

\author{
Joseph M. Pletcher and Frank E. McDonald* \\ Department of Chemistry, Emory University, Atlanta, GA 30322
}

\section{SUPPORTING INFORMATION-part 2}

${ }^{1} \mathrm{H}$ and ${ }^{13} \mathrm{C}$ NMR spectra for new compounds 
${ }^{1} \mathrm{H}$ spectrum of $4 \mathbf{a}\left(600 \mathrm{MHz}, \mathrm{CDCl}_{3}\right)$ :

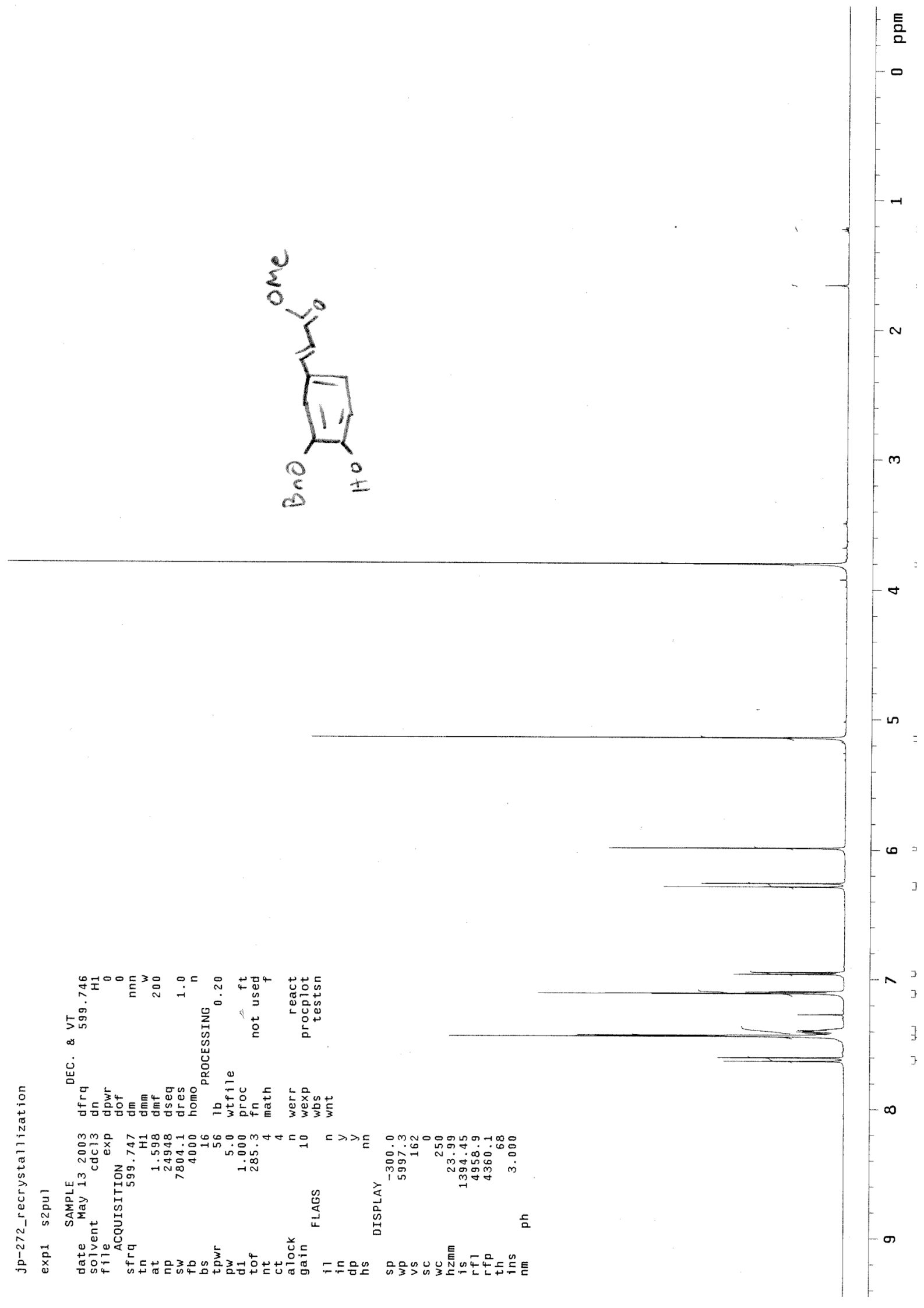


${ }^{13} \mathrm{C}$ spectrum of $4 \mathrm{a}\left(150 \mathrm{MHz}, \mathrm{CDCl}_{3}\right)$ :

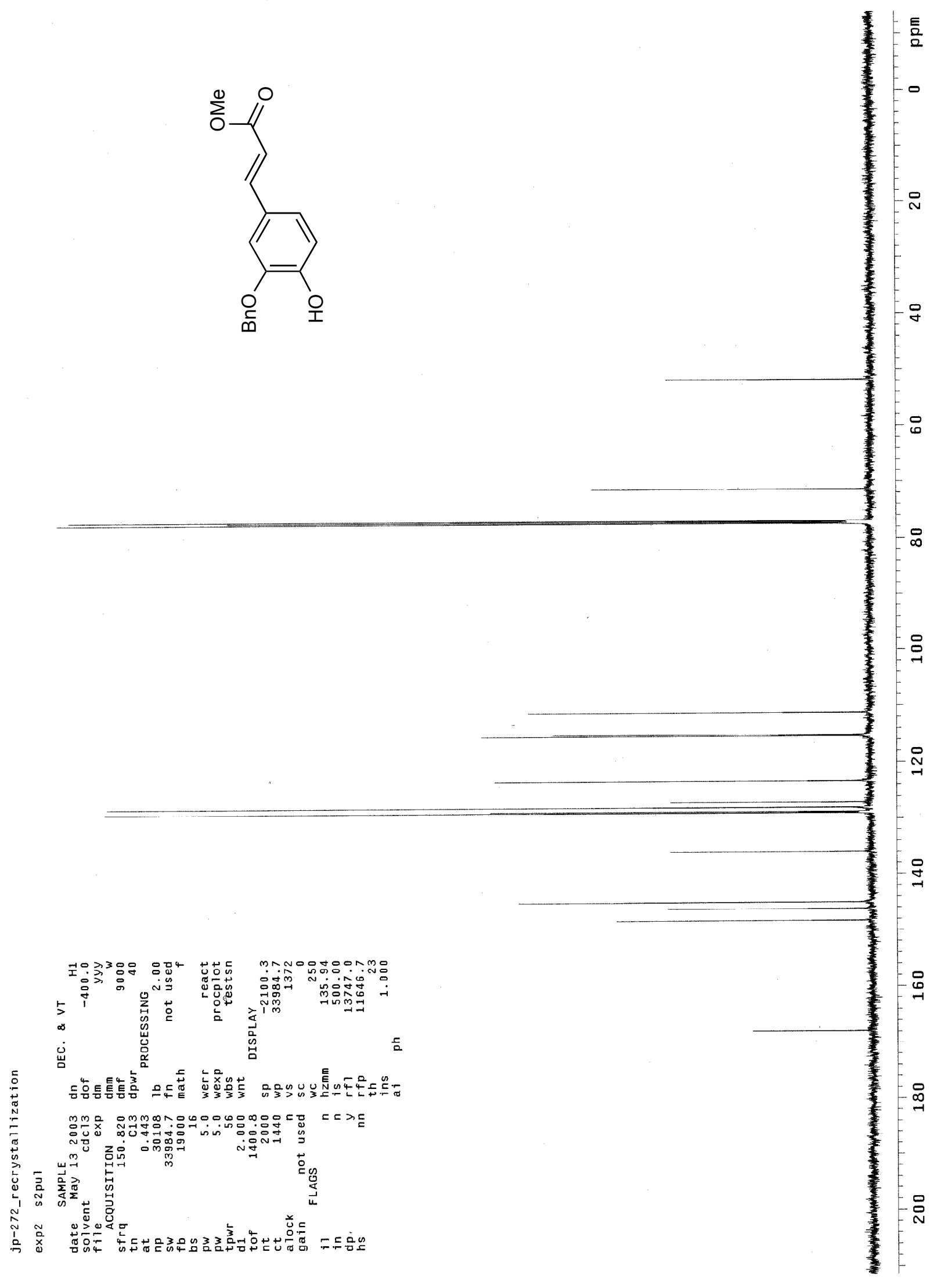


${ }^{1} \mathrm{H}$ spectrum of $\mathbf{4 b}\left(600 \mathrm{MHz}, \mathrm{CDCl}_{3}\right)$ :

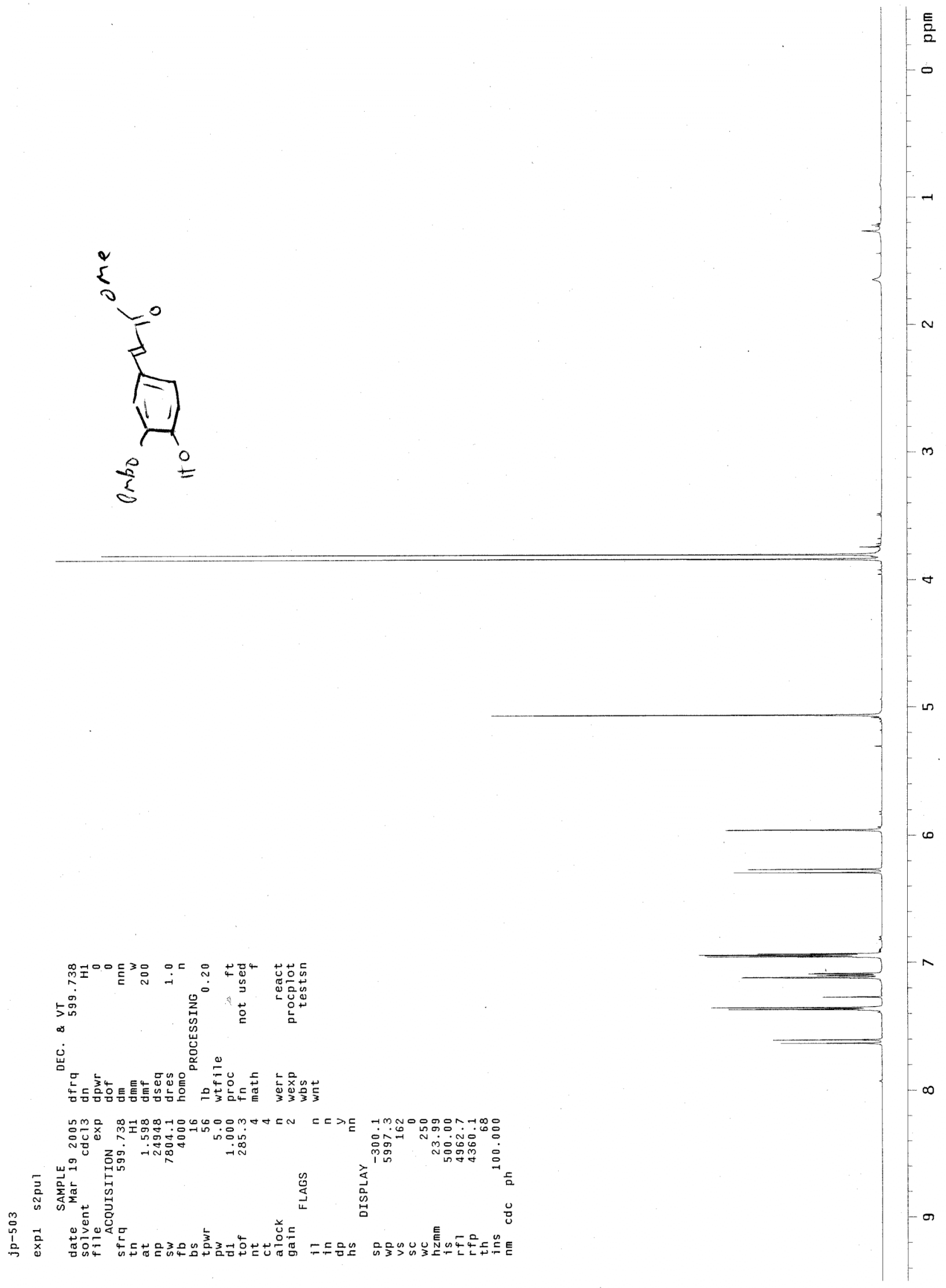


${ }^{13} \mathrm{C}$ spectrum of $\mathbf{4 b}\left(100 \mathrm{MHz}, \mathrm{CDCl}_{3}\right)$ :

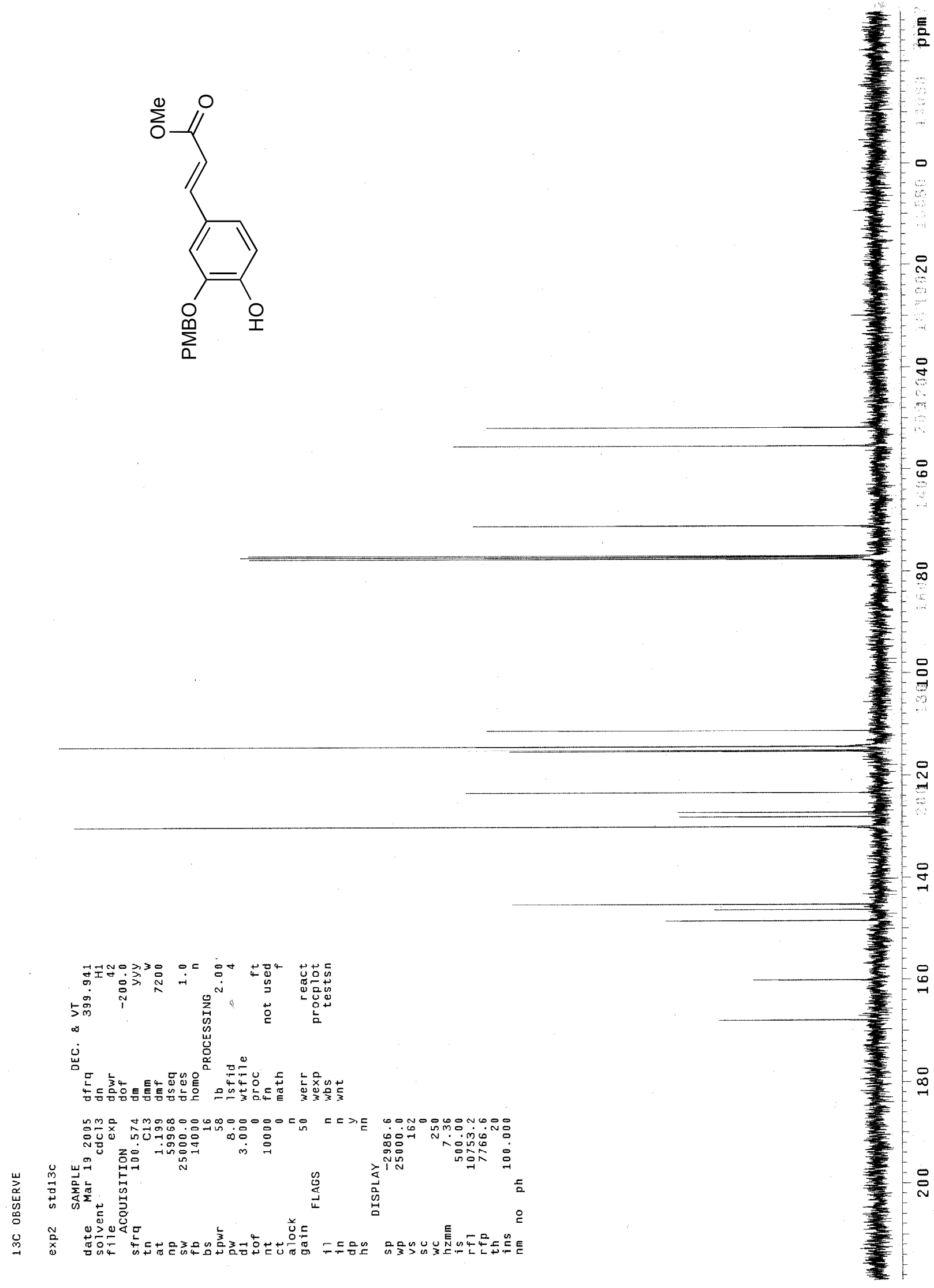


${ }^{1} \mathrm{H}$ spectrum of $6 \mathbf{a}\left(600 \mathrm{MHz}, \mathrm{CDCl}_{3}\right)$ :

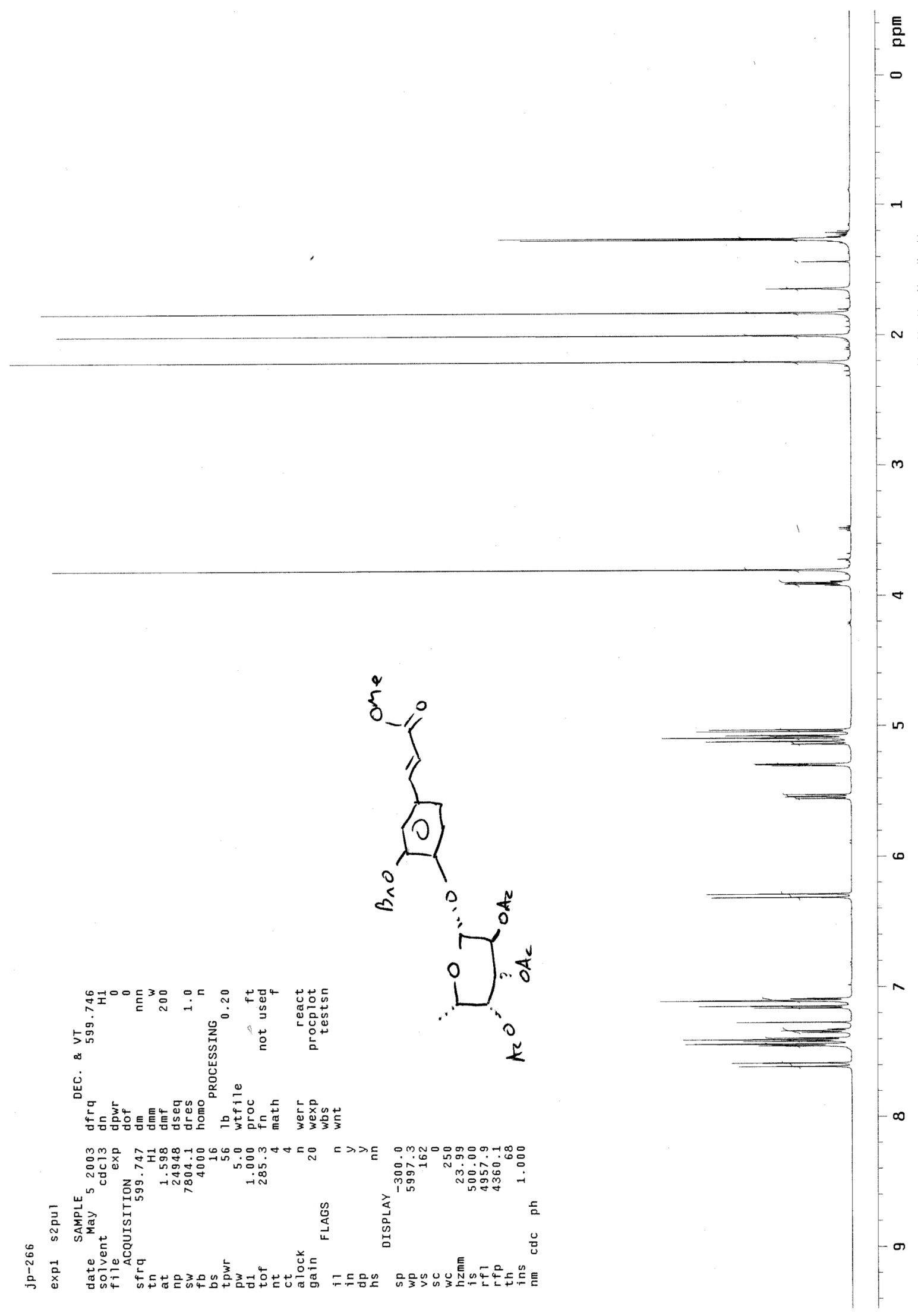


${ }^{13} \mathrm{C}$ spectrum of $6 \mathrm{a}\left(150 \mathrm{MHz}, \mathrm{CDCl}_{3}\right)$ :

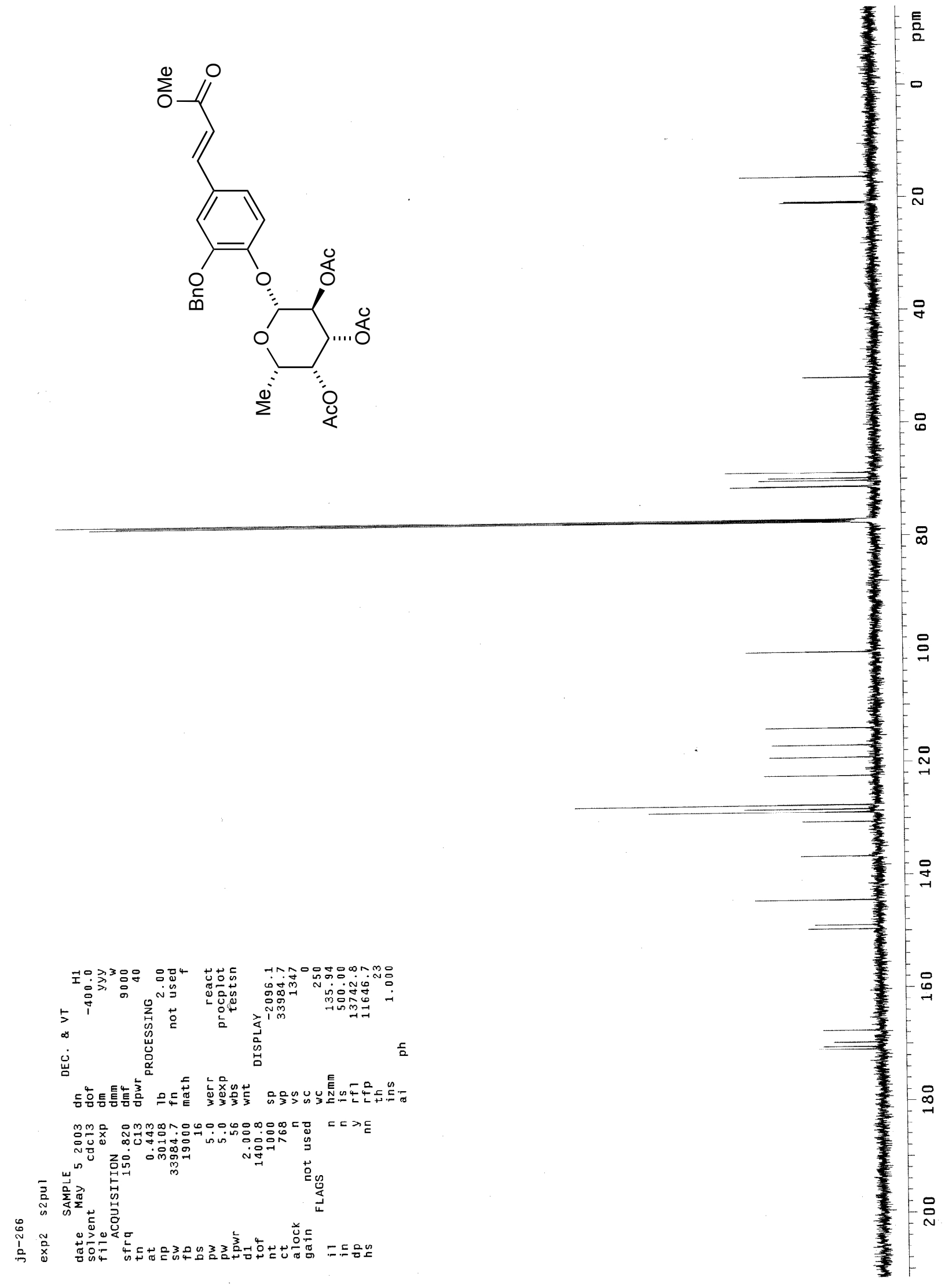


${ }^{1} \mathrm{H}$ spectrum of $\mathbf{6 b}\left(600 \mathrm{MHz}, \mathrm{CDCl}_{3}\right)$ :

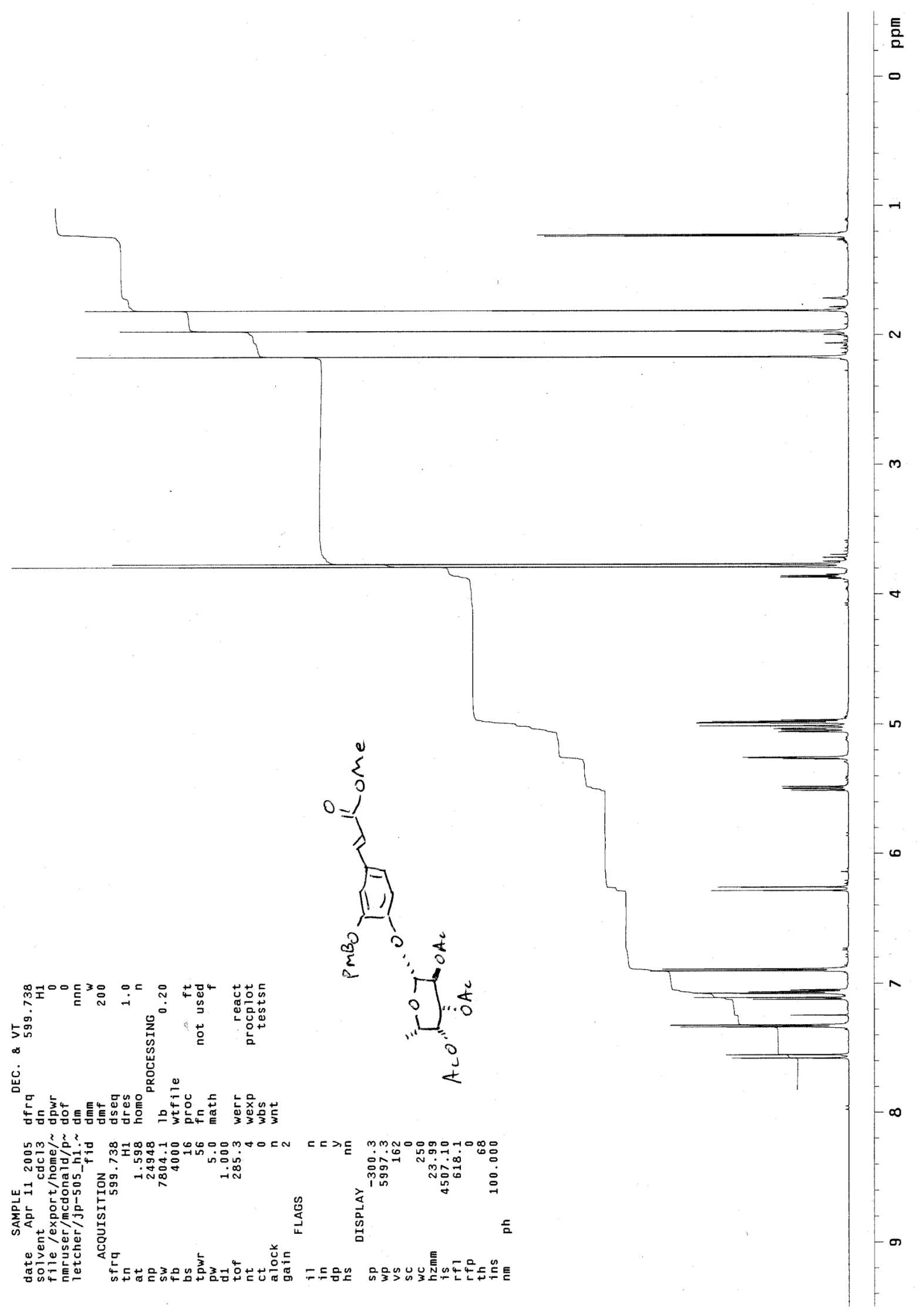


${ }^{13} \mathrm{C}$ spectrum of $\mathbf{6 b}\left(150 \mathrm{MHz}, \mathrm{CDCl}_{3}\right)$ :

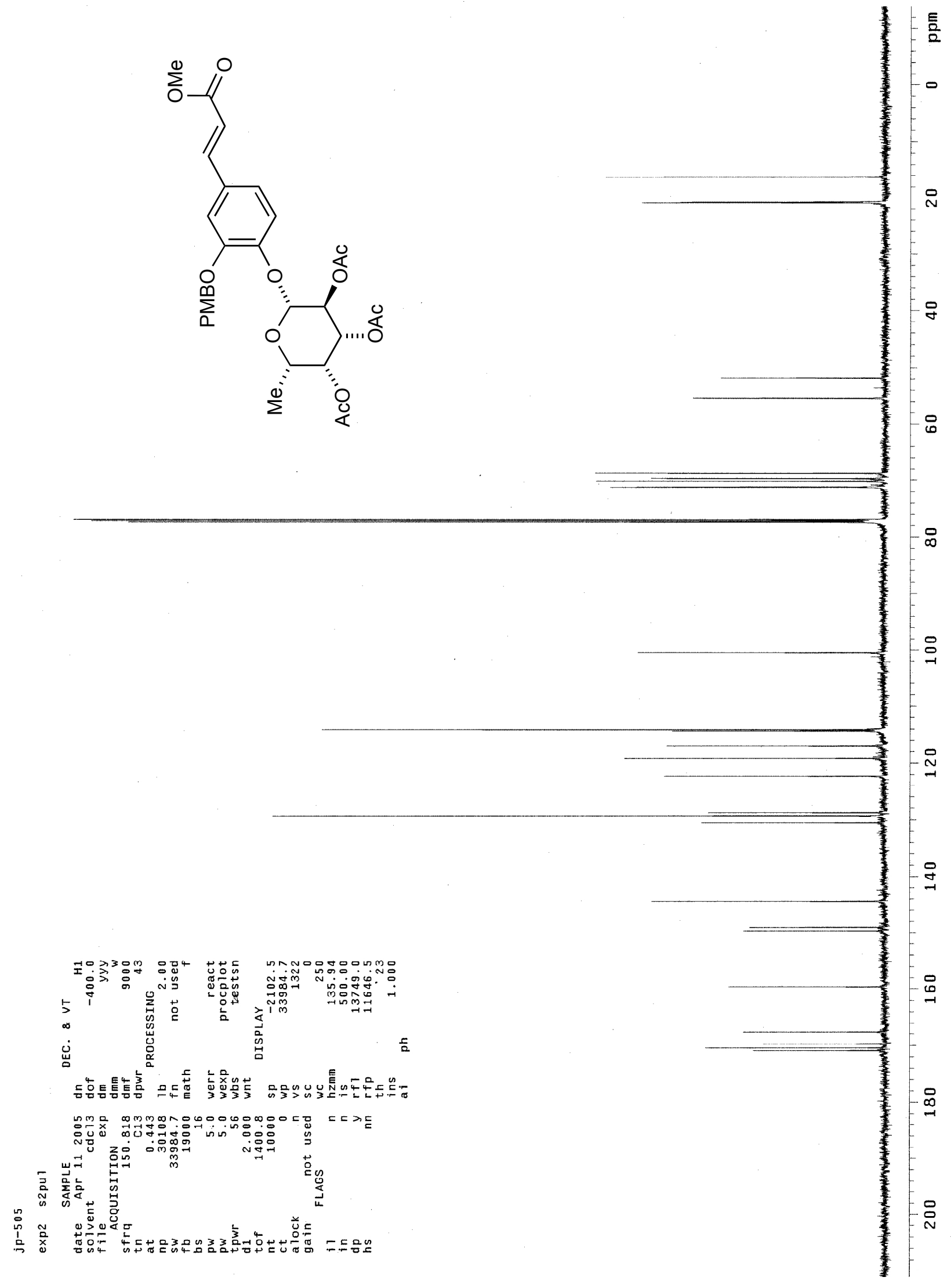


${ }^{1} \mathrm{H}$ spectrum of $6 \mathbf{c}\left(600 \mathrm{MHz}, \mathrm{CDCl}_{3}\right)$ :

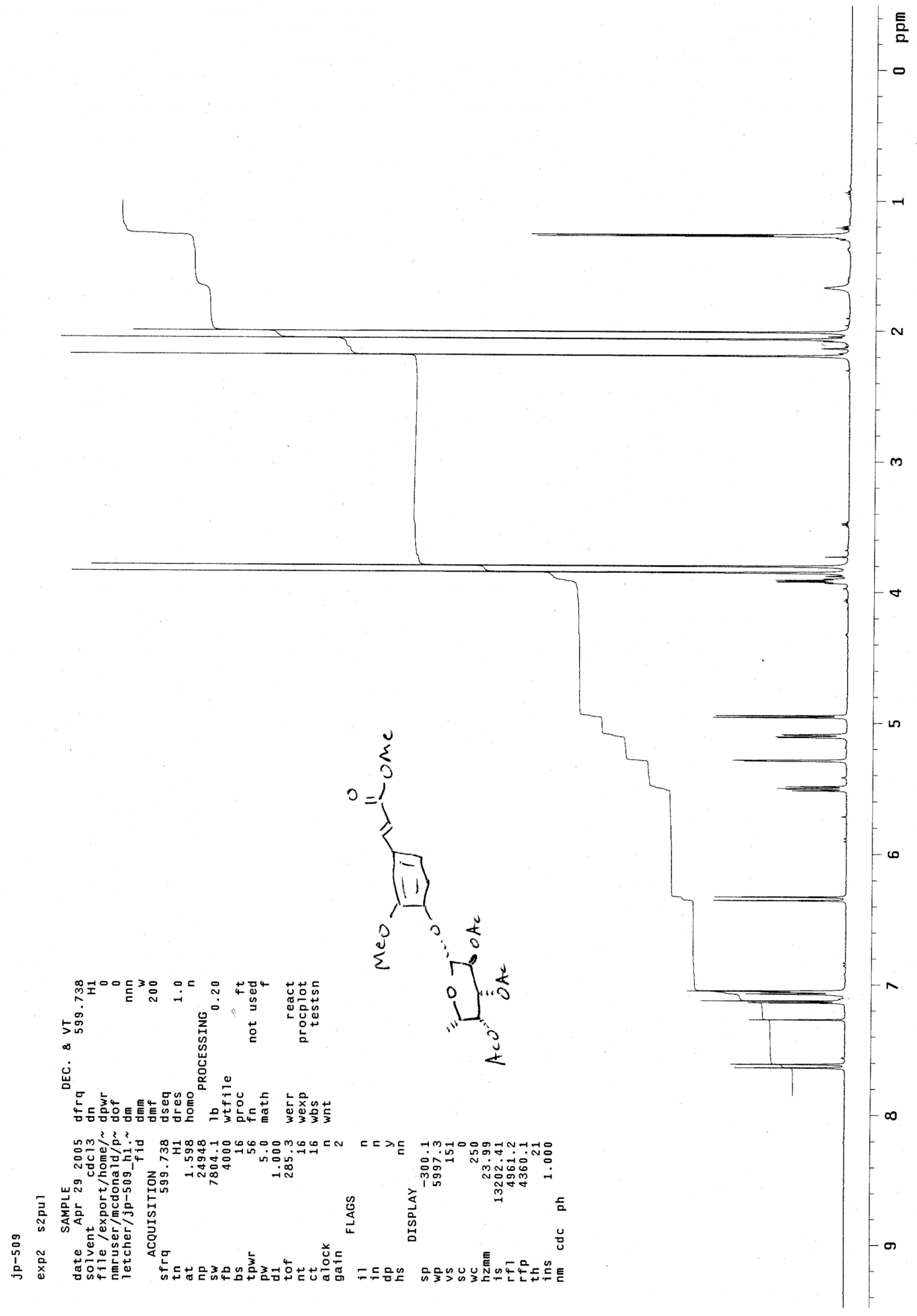


${ }^{13} \mathrm{C}$ spectrum of $6 \mathrm{c}\left(150 \mathrm{MHz}, \mathrm{CDCl}_{3}\right)$ :
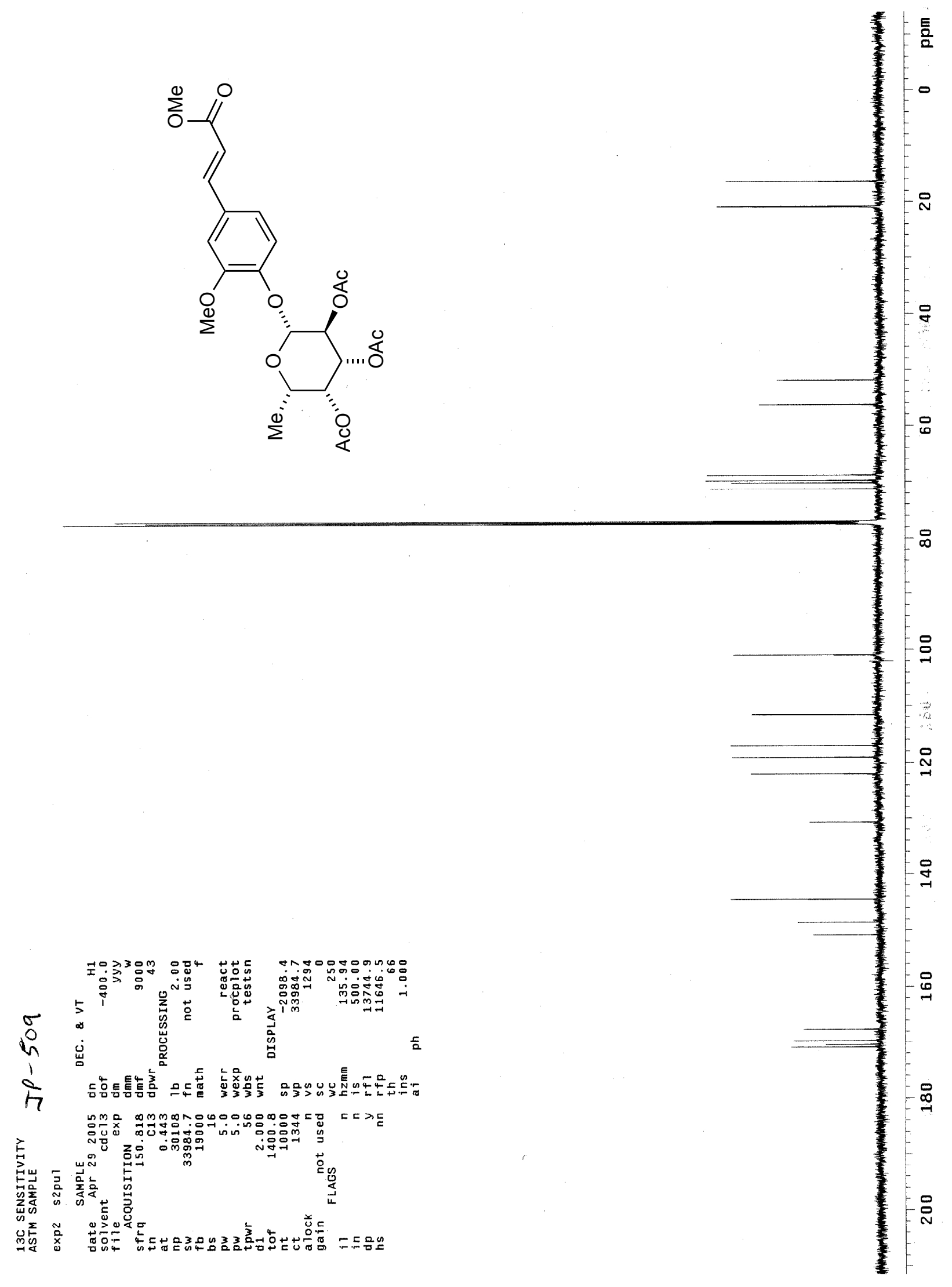
${ }^{1} \mathrm{H}$ spectrum of intermediate to $7 \mathrm{a}\left(600 \mathrm{MHz}, \mathrm{CD}_{3} \mathrm{OD}\right)$ :
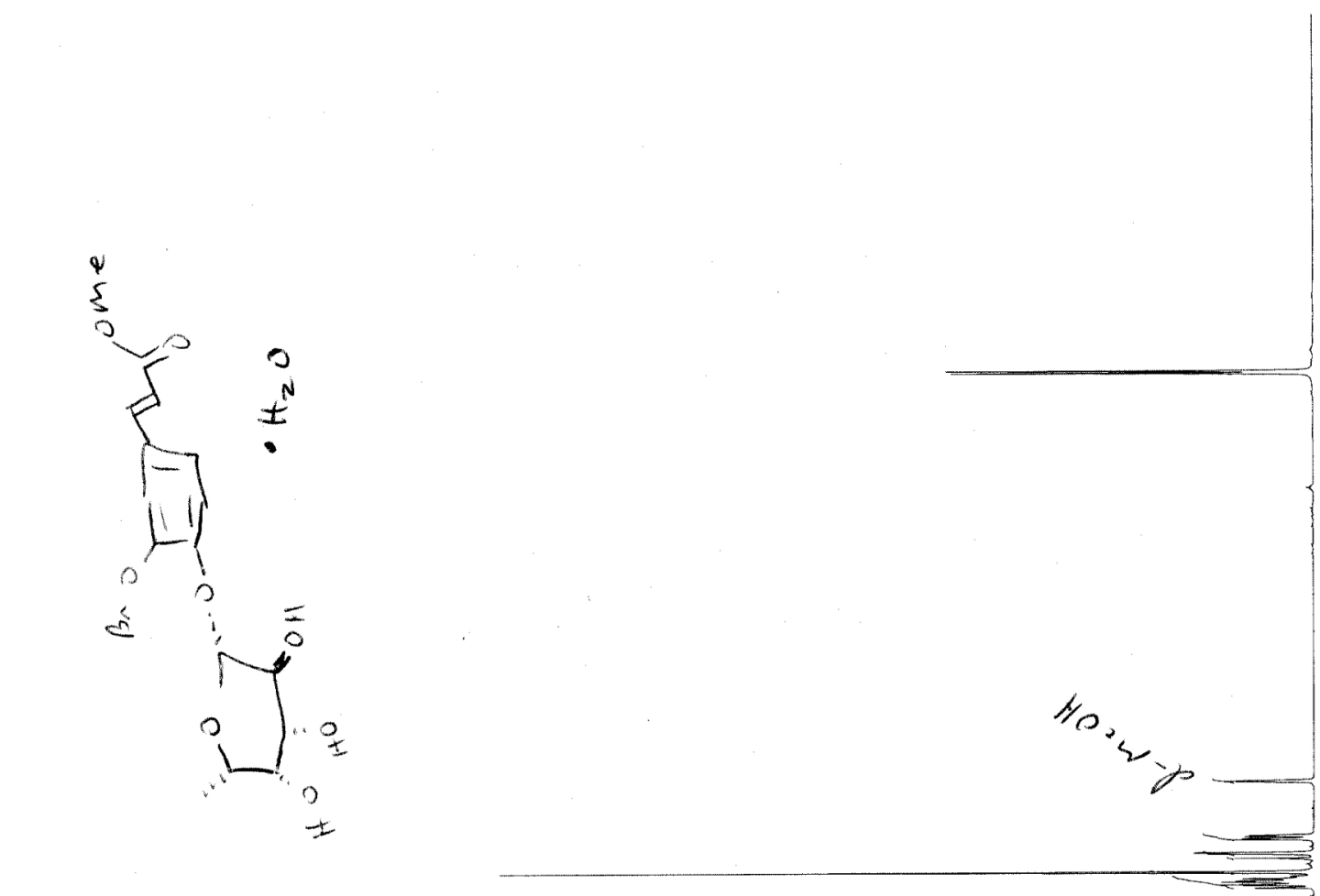

r
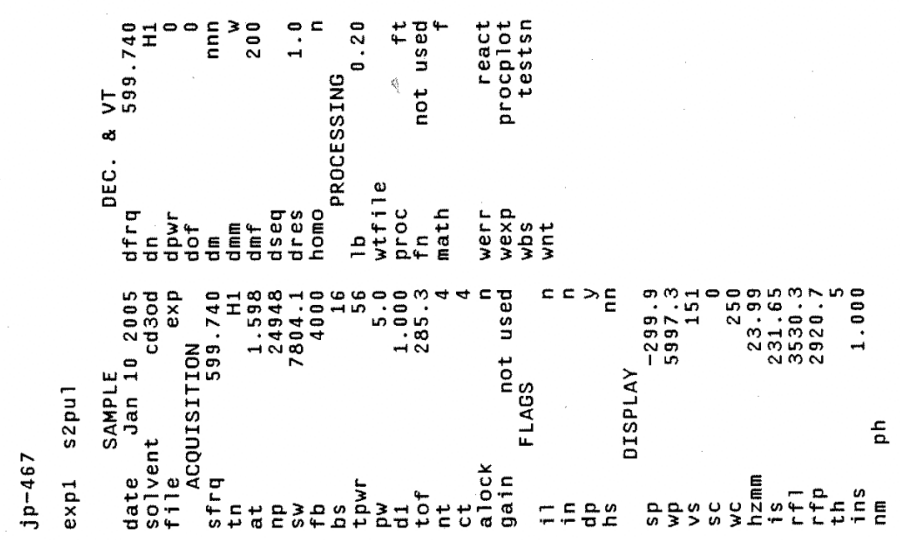

高 
${ }^{13} \mathrm{C}$ spectrum of intermediate to $7 \mathrm{a}\left(150 \mathrm{MHz}, \mathrm{CD}_{3} \mathrm{OD}\right)$ :

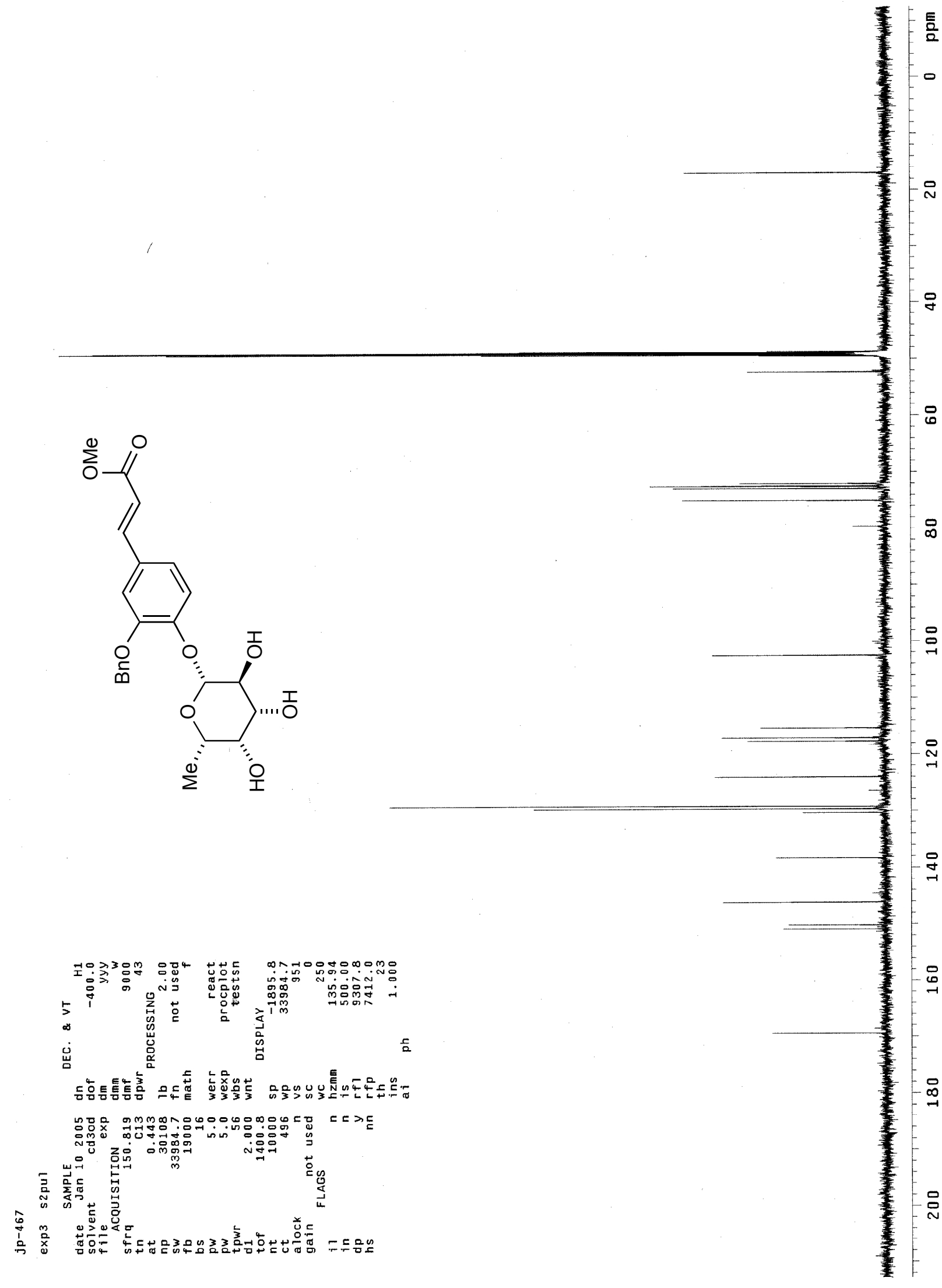


${ }^{1} \mathrm{H}$ spectrum of intermediate to $7 \mathbf{b}\left(600 \mathrm{MHz}, \mathrm{CD}_{3} \mathrm{OD}\right)$ :

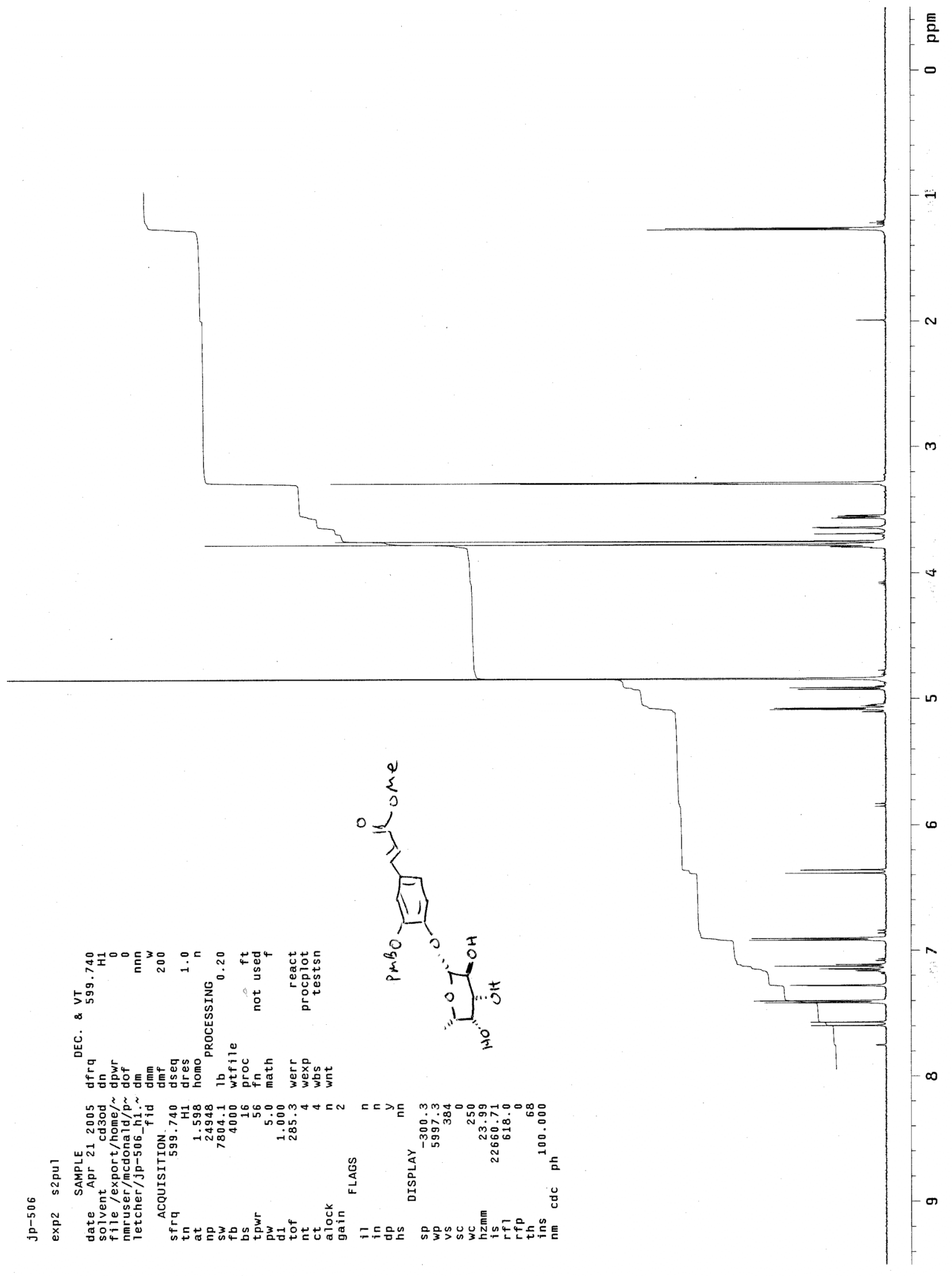


${ }^{13} \mathrm{C}$ spectrum of intermediate to $\mathbf{7 b}\left(100 \mathrm{MHz}, \mathrm{CD}_{3} \mathrm{OD}\right)$ :

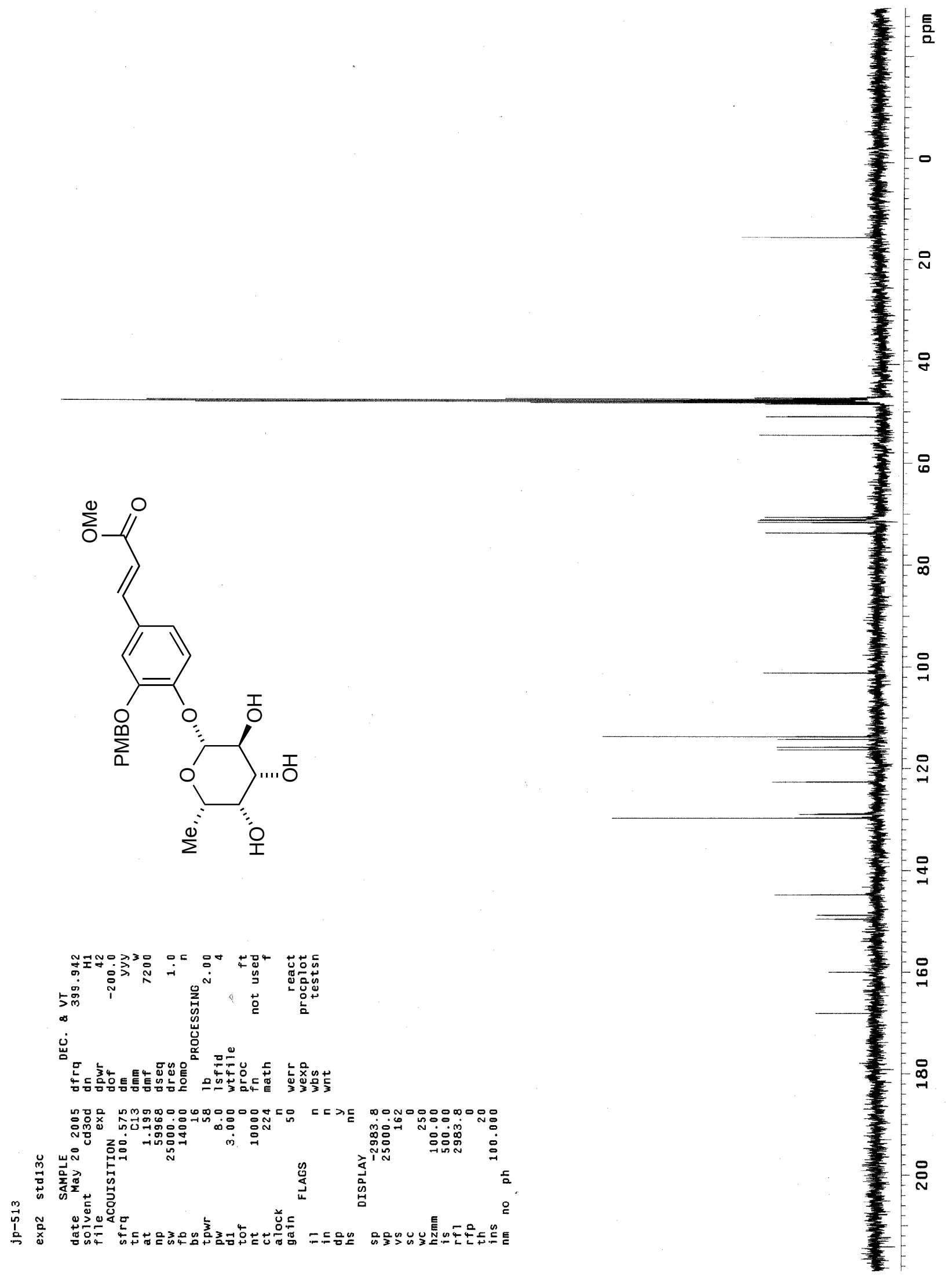


${ }^{1} \mathrm{H}$ spectrum of $7 \mathbf{a}\left(600 \mathrm{MHz}, \mathrm{CDCl}_{3}\right)$ :

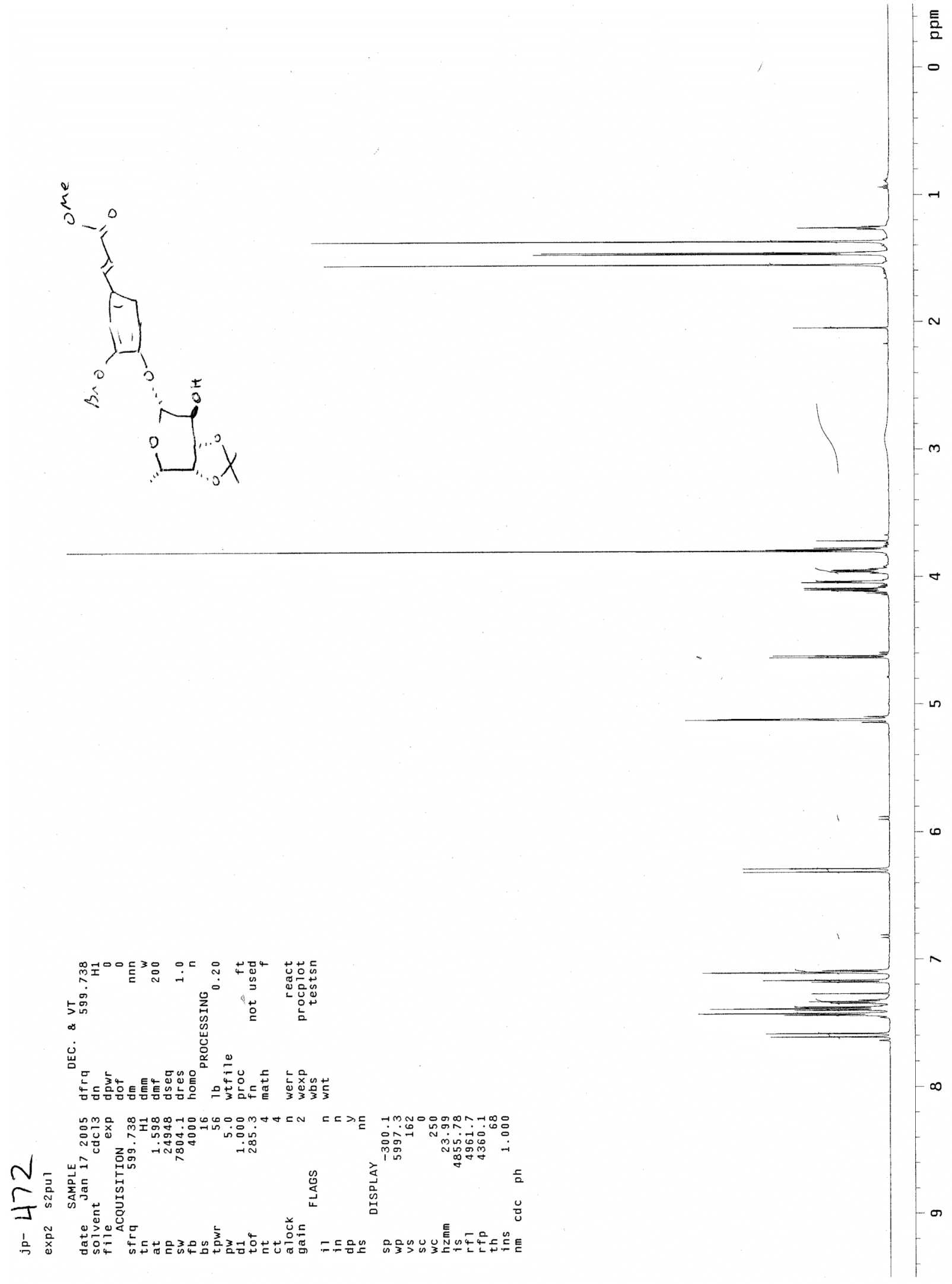


${ }^{13} \mathrm{C}$ spectrum of $7 \mathrm{a}\left(150 \mathrm{MHz}, \mathrm{CDCl}_{3}\right)$ :

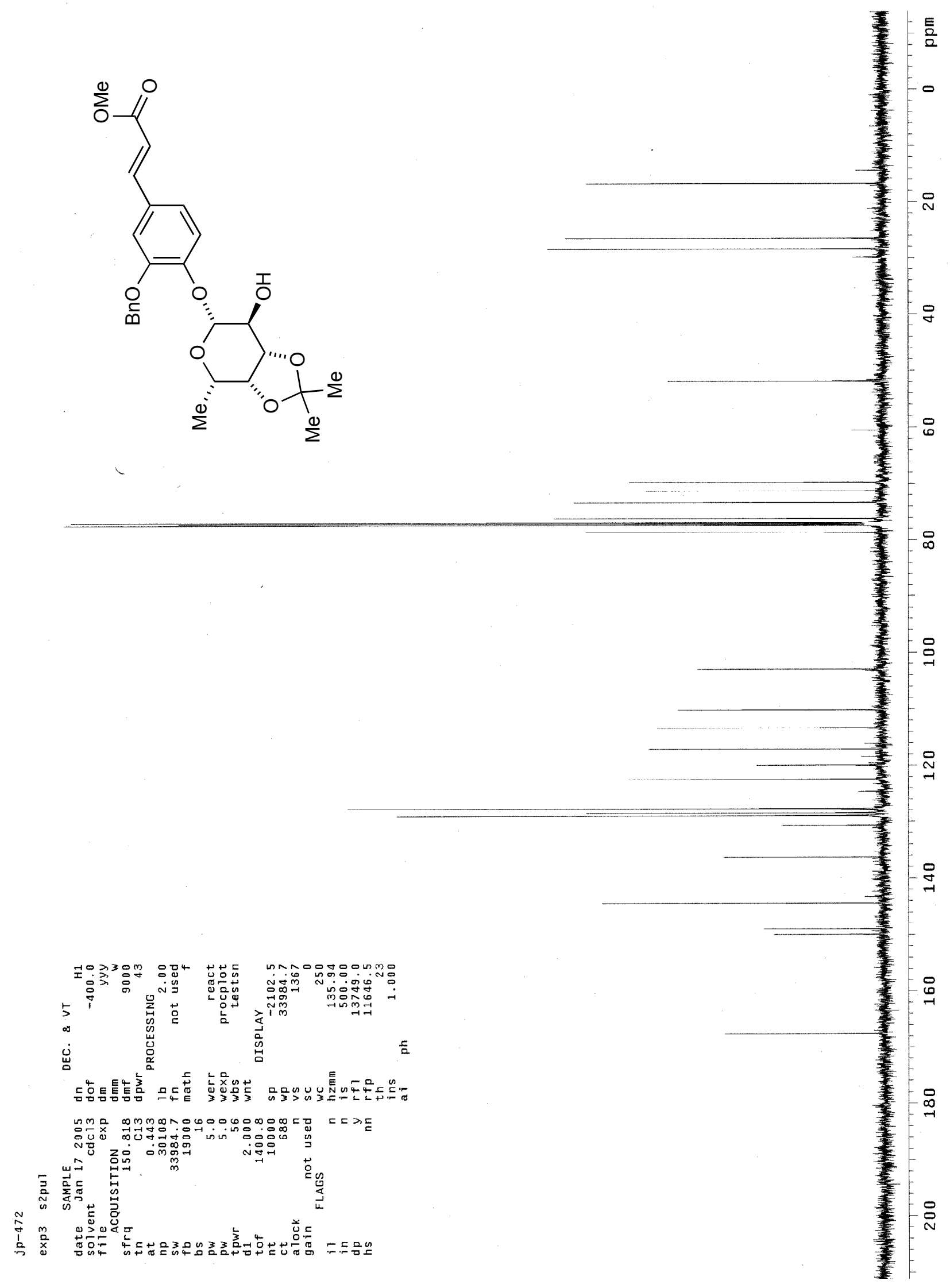


${ }^{1} \mathrm{H}$ spectrum of $7 \mathbf{b}\left(600 \mathrm{MHz}, \mathrm{CDCl}_{3}\right)$ :

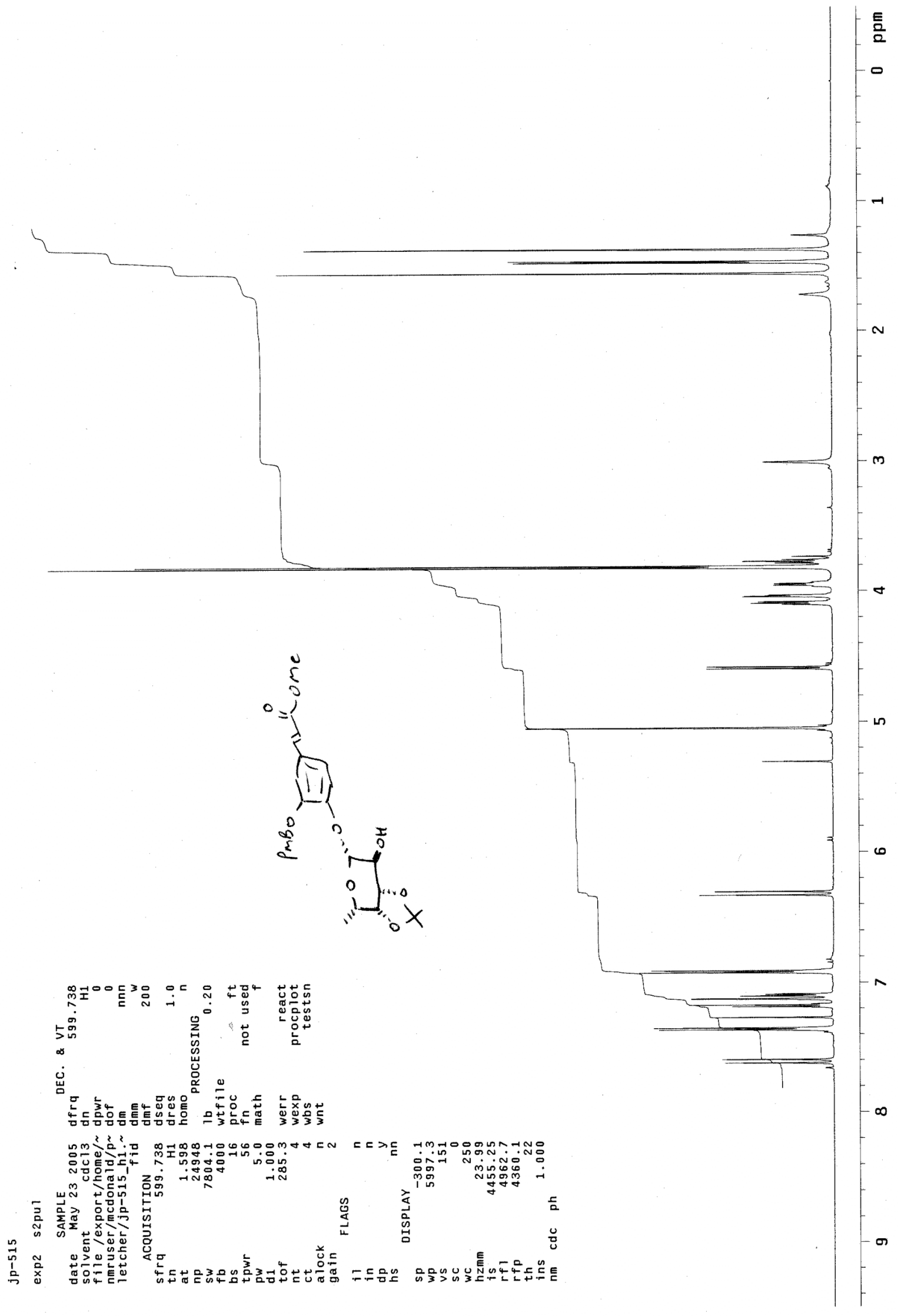


${ }^{13} \mathrm{C}$ spectrum of $\mathbf{7 b}\left(150 \mathrm{MHz}, \mathrm{CDCl}_{3}\right)$ :

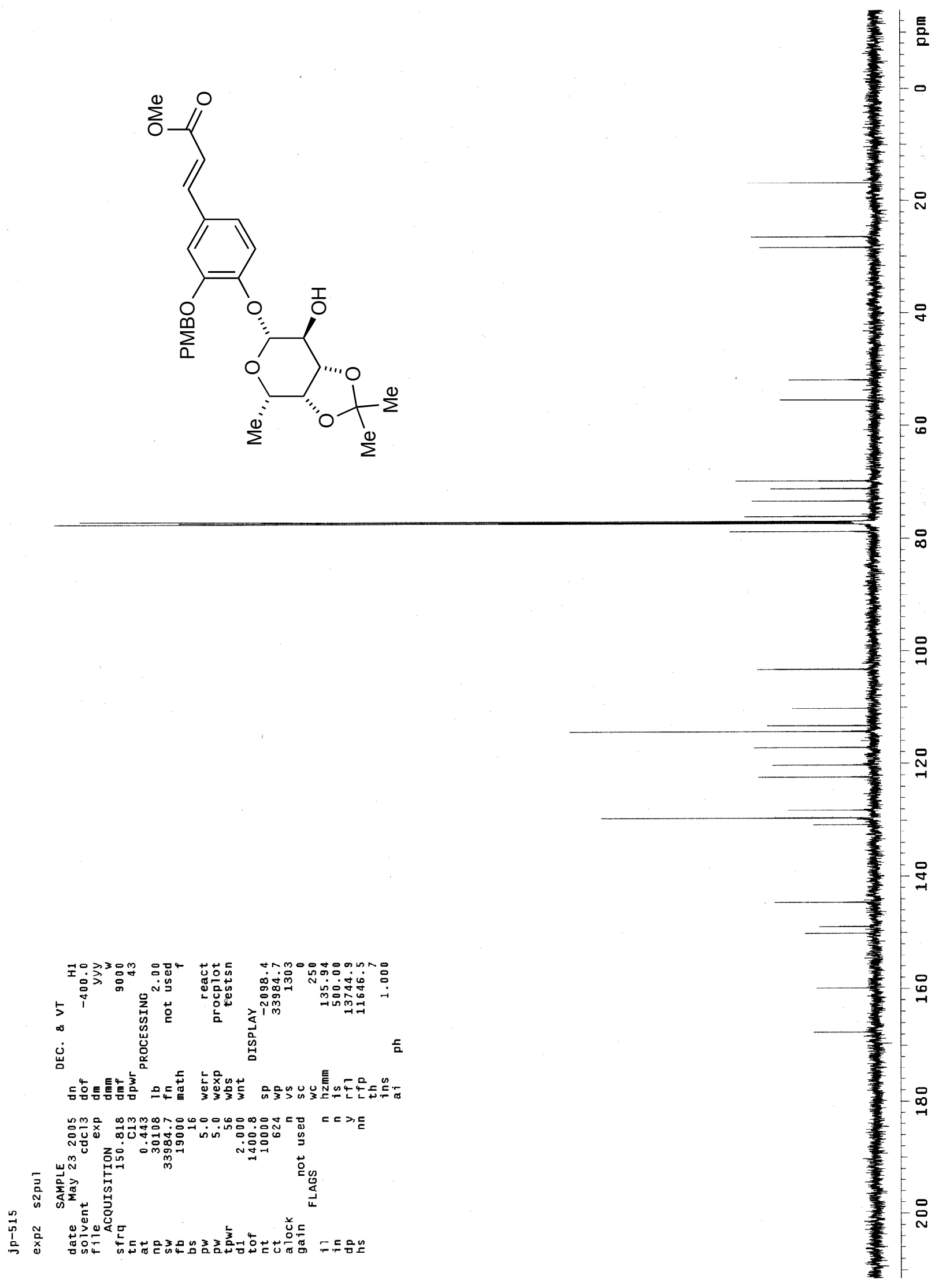


${ }^{1} \mathrm{H}$ spectrum of $8 \mathbf{a}\left(600 \mathrm{MHz}, \mathrm{CD}_{3} \mathrm{OD}\right)$ :

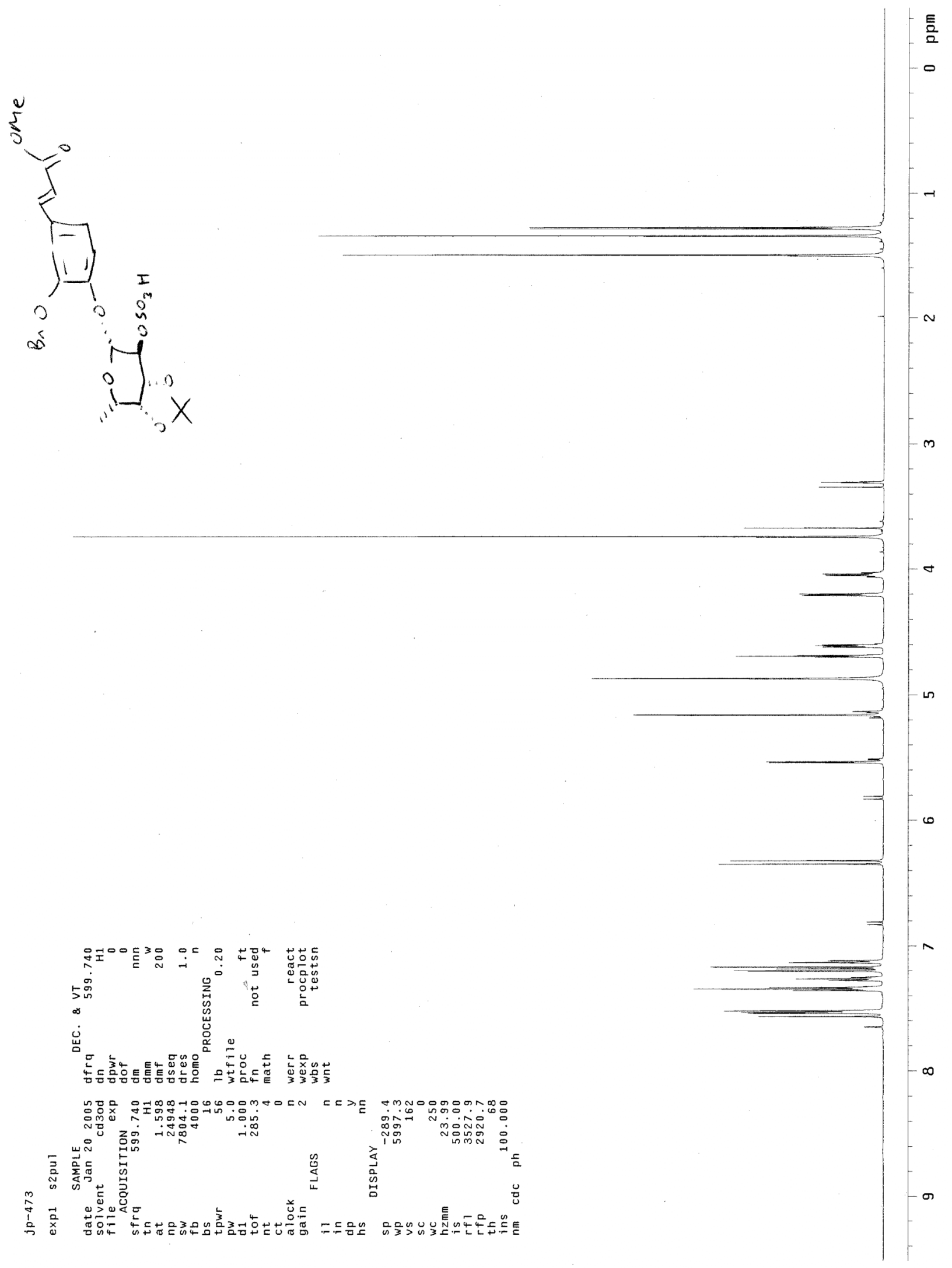


${ }^{13} \mathrm{C}$ spectrum of $8 \mathbf{a}\left(150 \mathrm{MHz}, \mathrm{CD}_{3} \mathrm{OD}\right)$ :

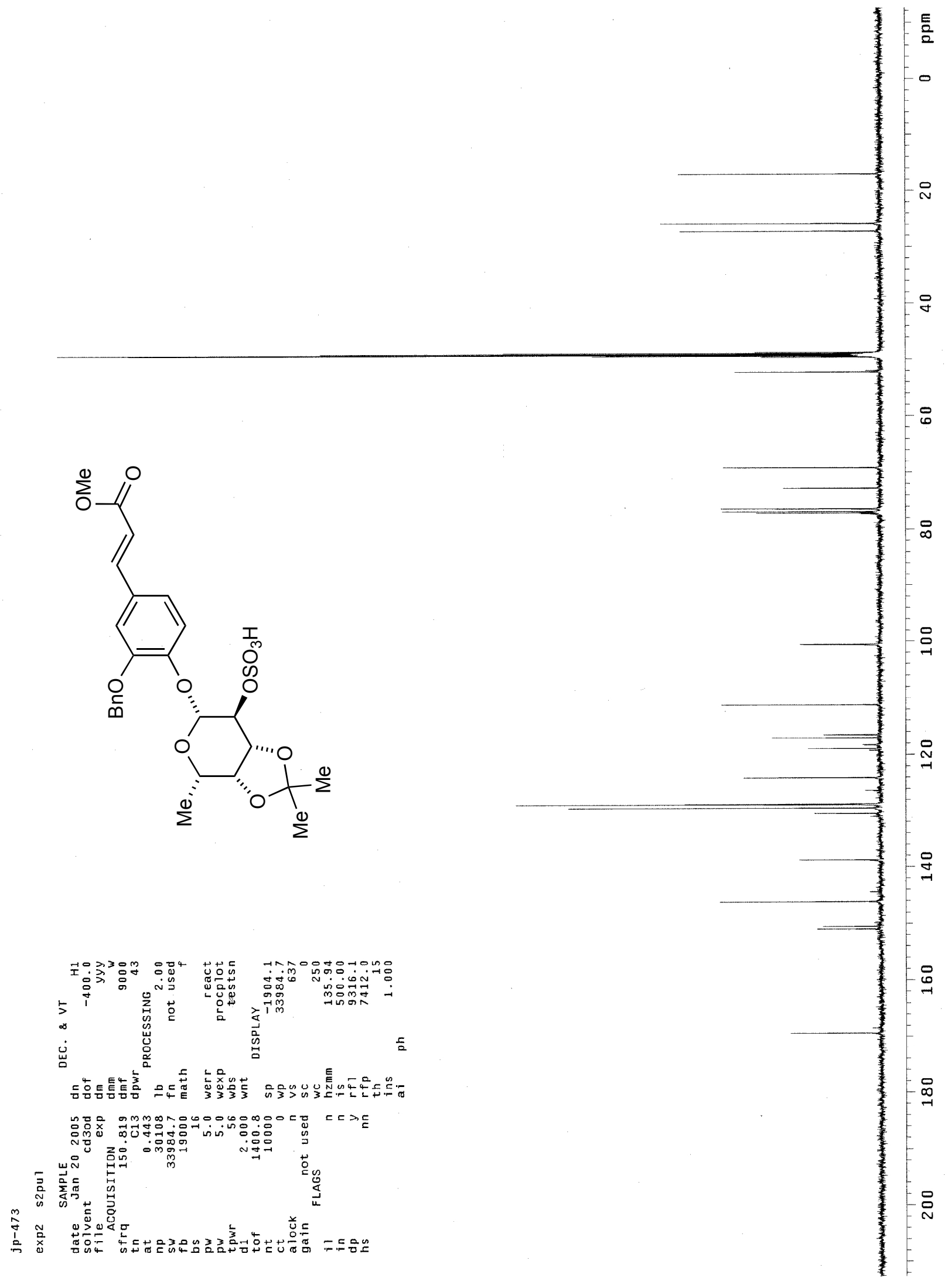


${ }^{1} \mathrm{H}$ spectrum of $\mathbf{8 b}\left(600 \mathrm{MHz}, \mathrm{CD}_{3} \mathrm{OD}\right)$ :

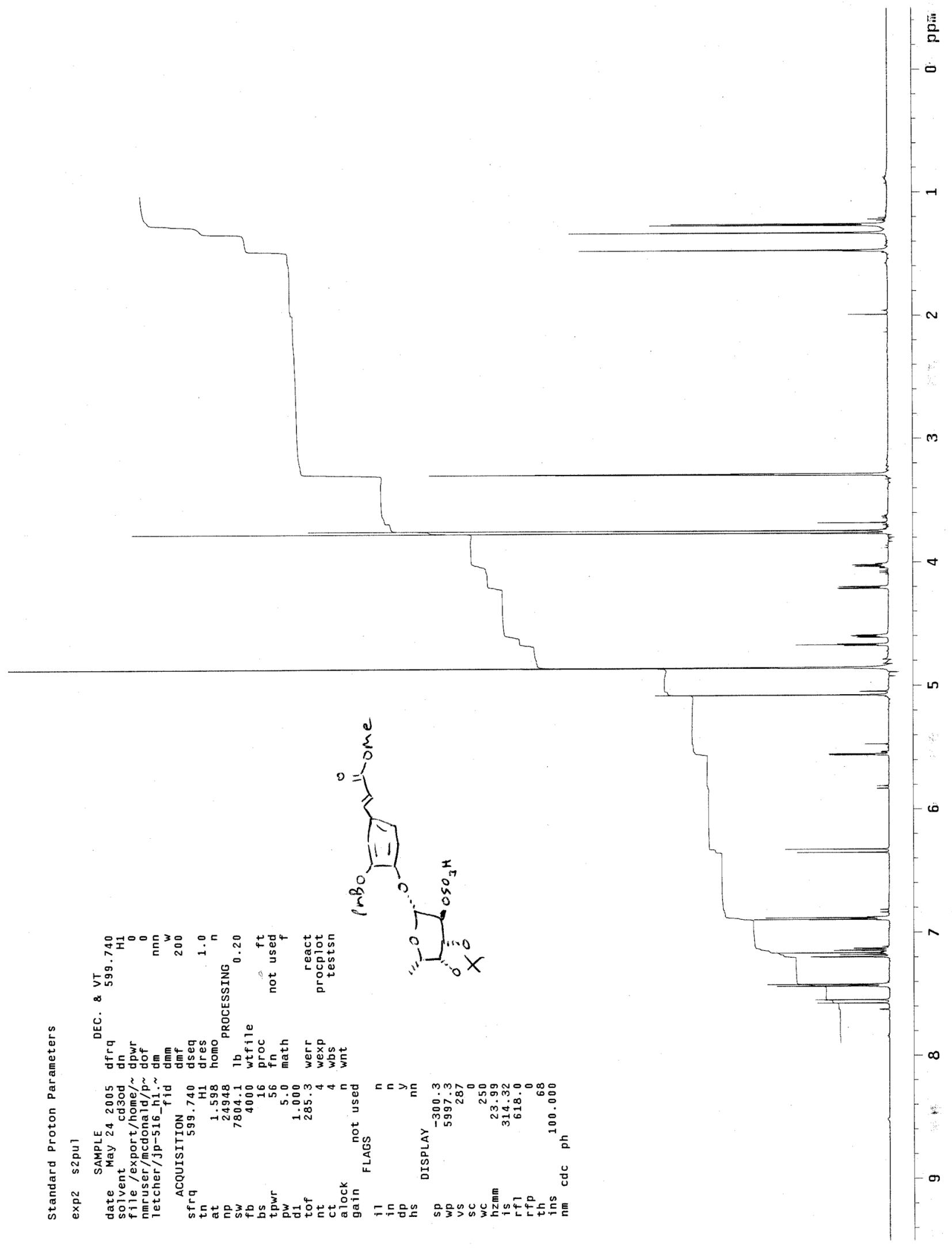


${ }^{13} \mathrm{C}$ spectrum of $8 \mathbf{b}\left(100 \mathrm{MHz}, \mathrm{CD}_{3} \mathrm{OD}\right)$ :
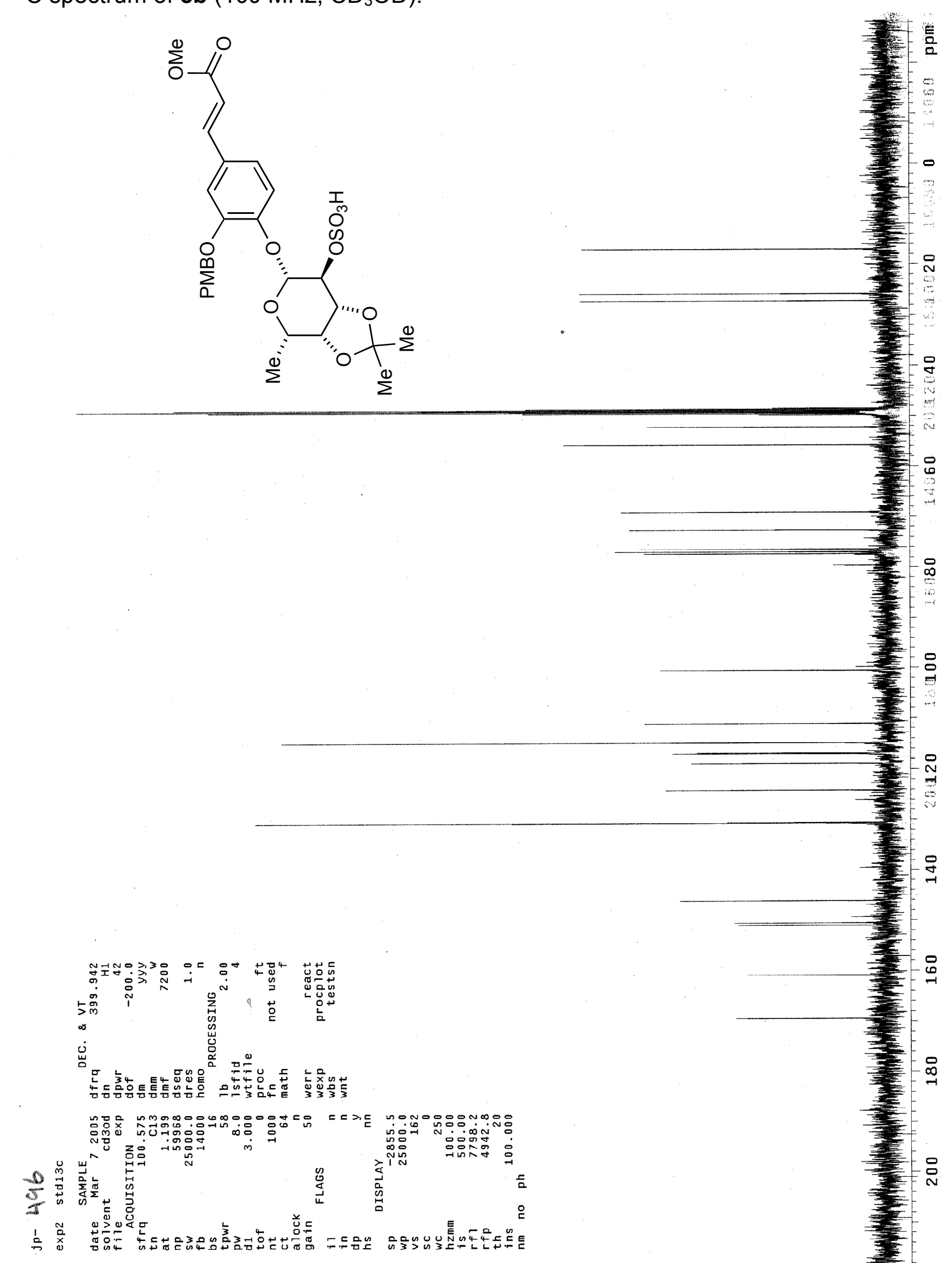
${ }^{1} \mathrm{H}$ spectrum of $9\left(600 \mathrm{MHz}, \mathrm{CD}_{3} \mathrm{OD}\right)$ :

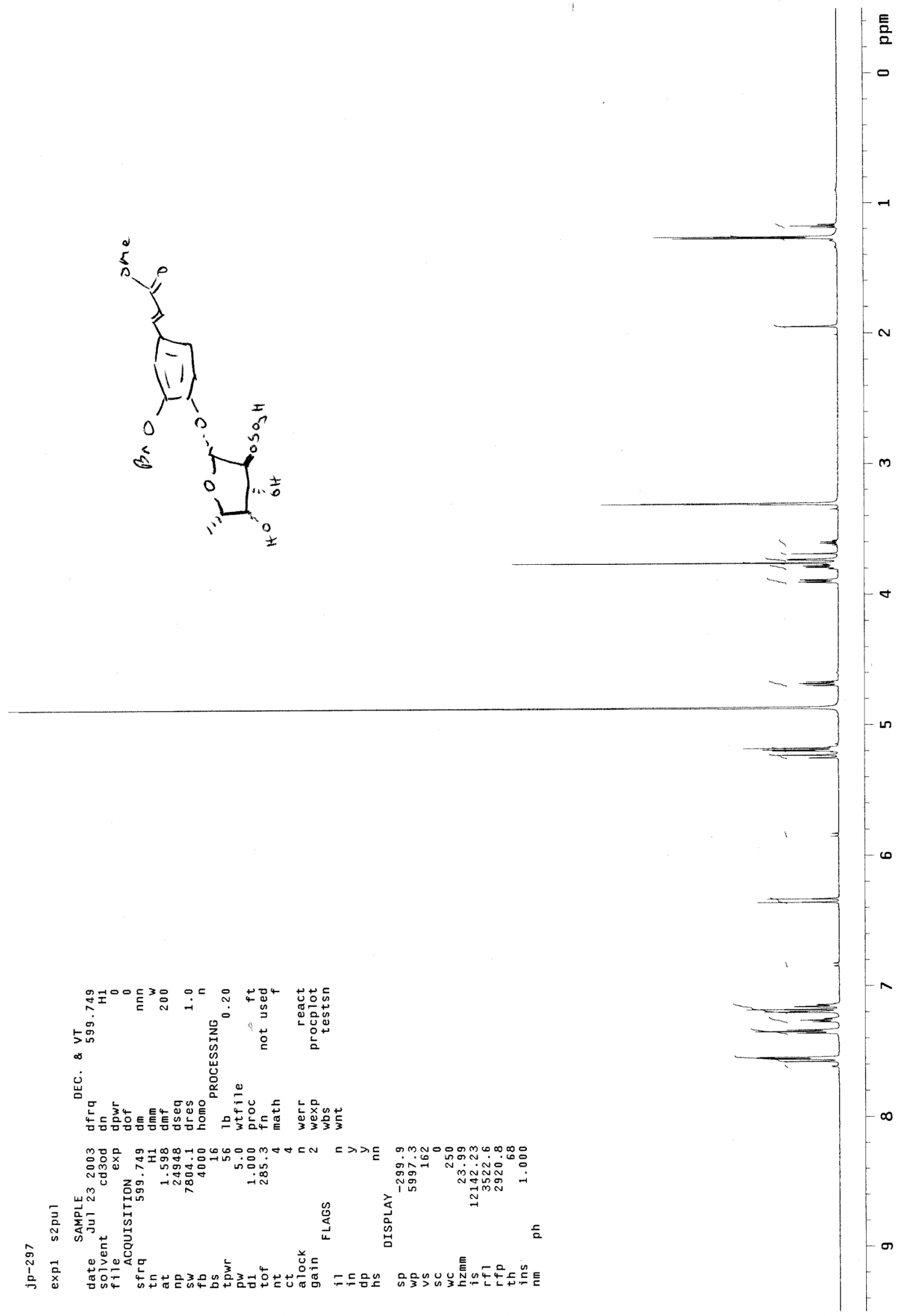


${ }^{1} \mathrm{H}$ spectrum of $10\left(600 \mathrm{MHz}, \mathrm{CD}_{3} \mathrm{OD}\right)$ :

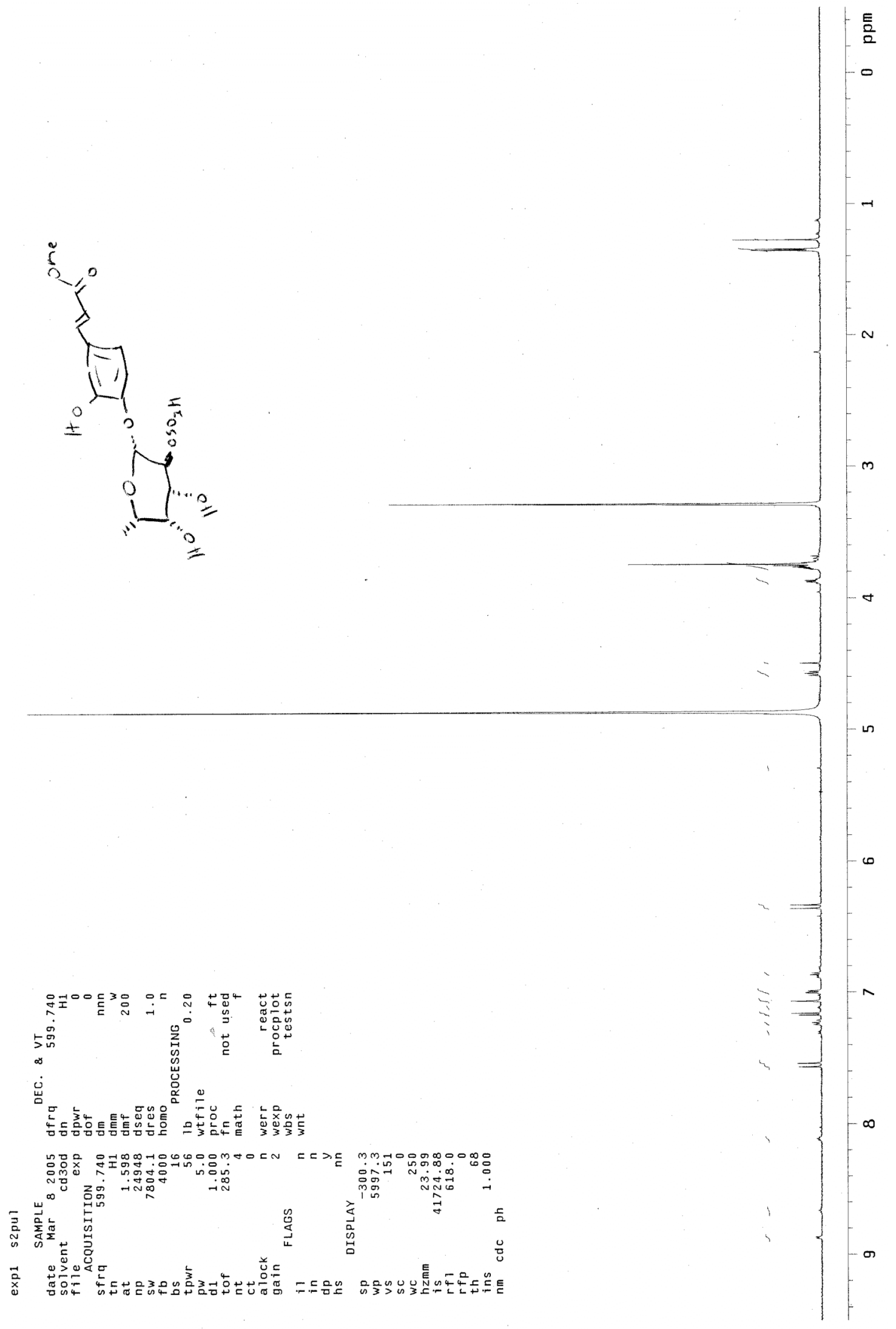


${ }^{1} \mathrm{H}$ spectrum of $11\left(600 \mathrm{MHz}, \mathrm{CD}_{3} \mathrm{OD}\right)$ :

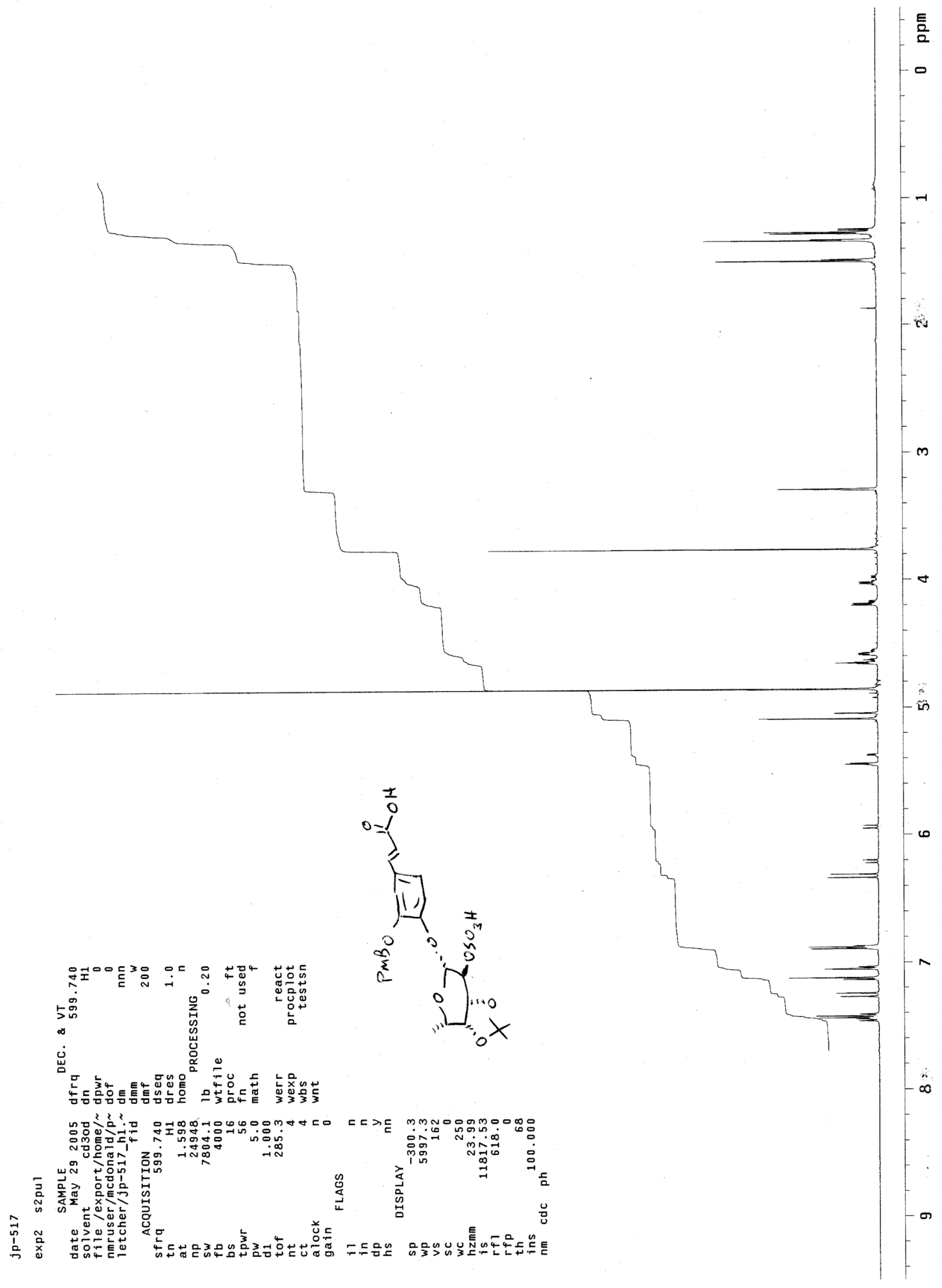


${ }^{13} \mathrm{C}$ spectrum of $11\left(150 \mathrm{MHz}, \mathrm{CD}_{3} \mathrm{OD}\right)$ :

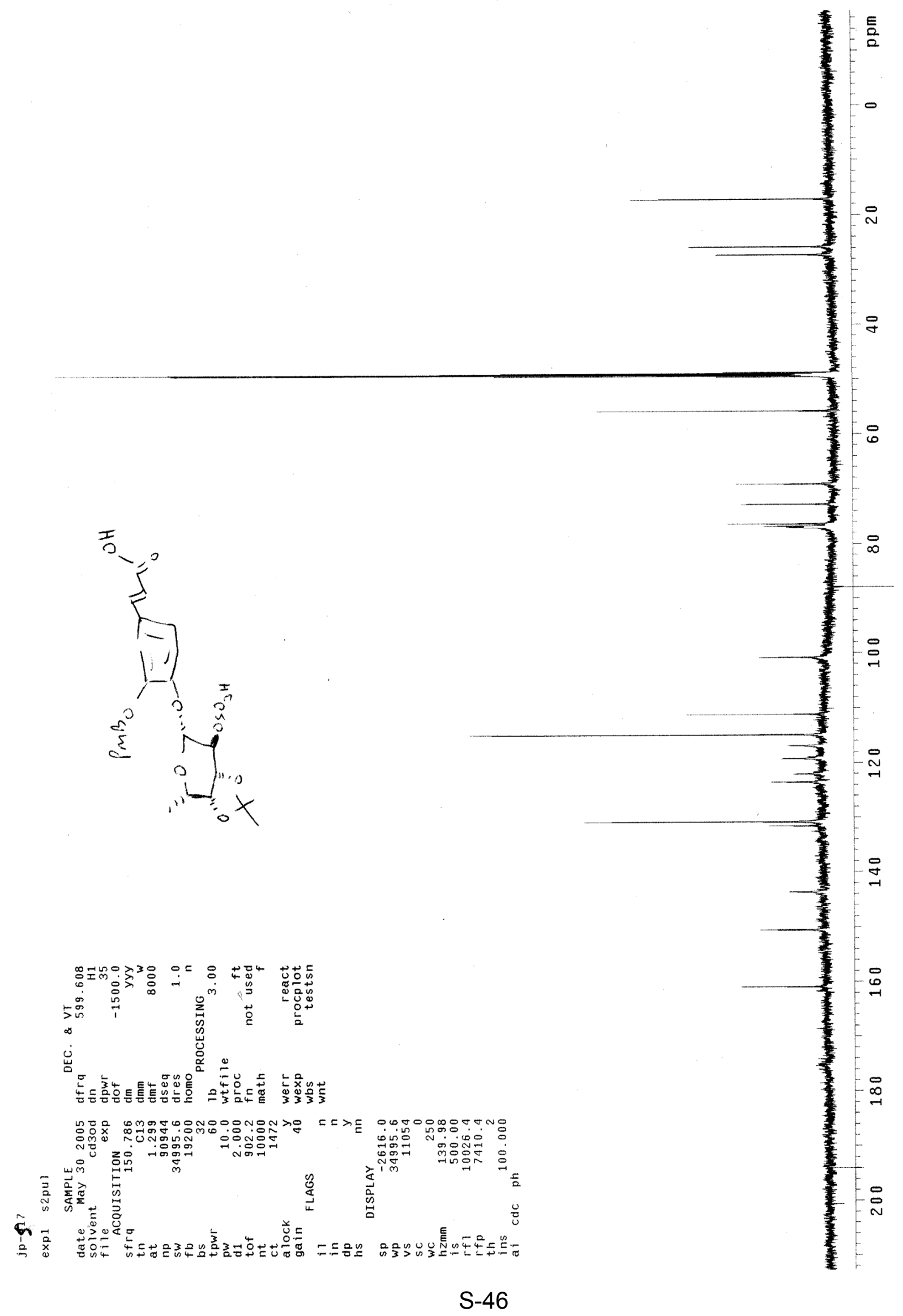


${ }^{1} \mathrm{H}$ spectrum of ent-3 $\left(600 \mathrm{MHz}, \mathrm{D}_{2} \mathrm{O}\right)$ :

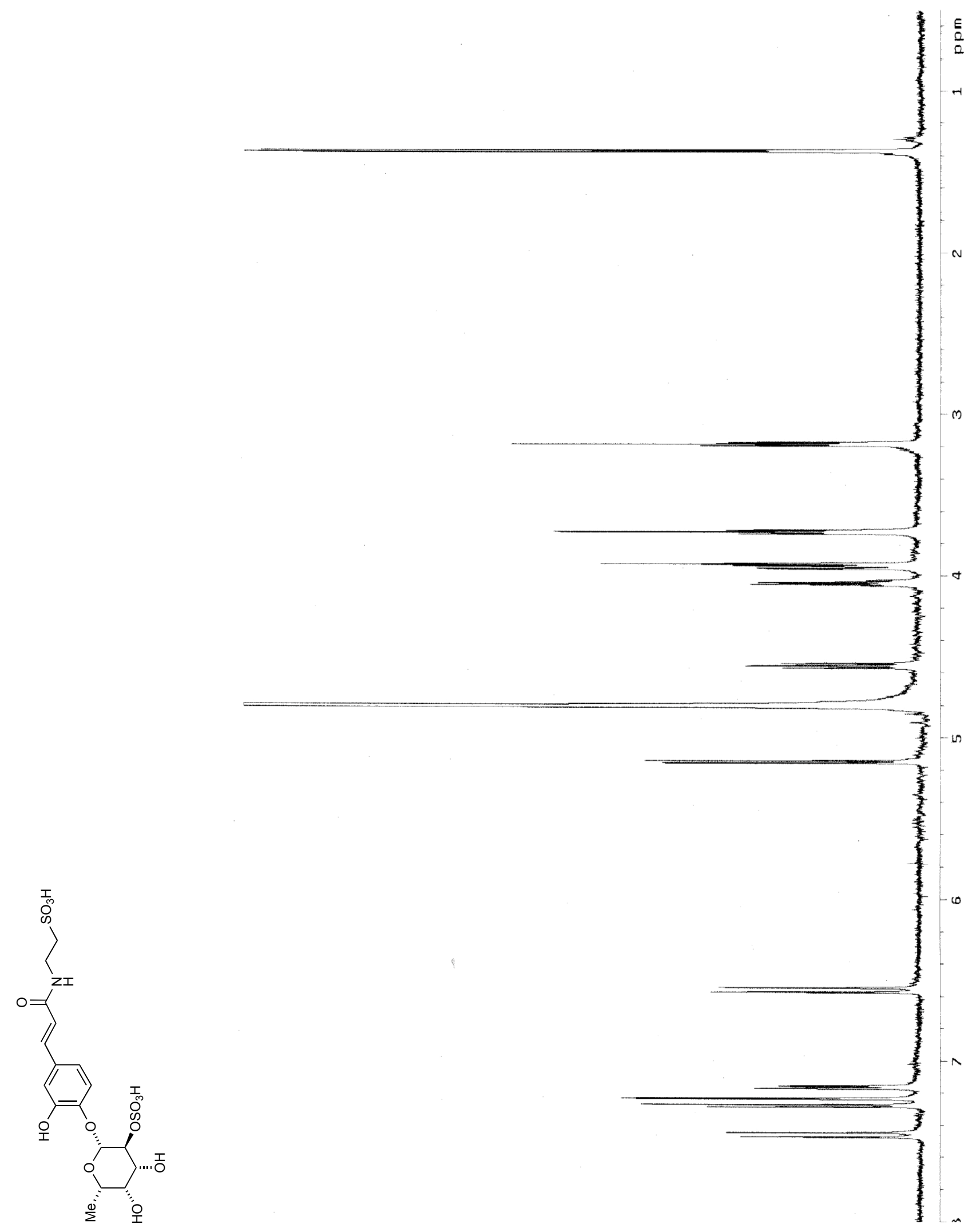


${ }^{13} \mathrm{C}$ spectrum of ent-3 $\left(150 \mathrm{MHz}, \mathrm{CD}_{3} \mathrm{OD}\right)$ :

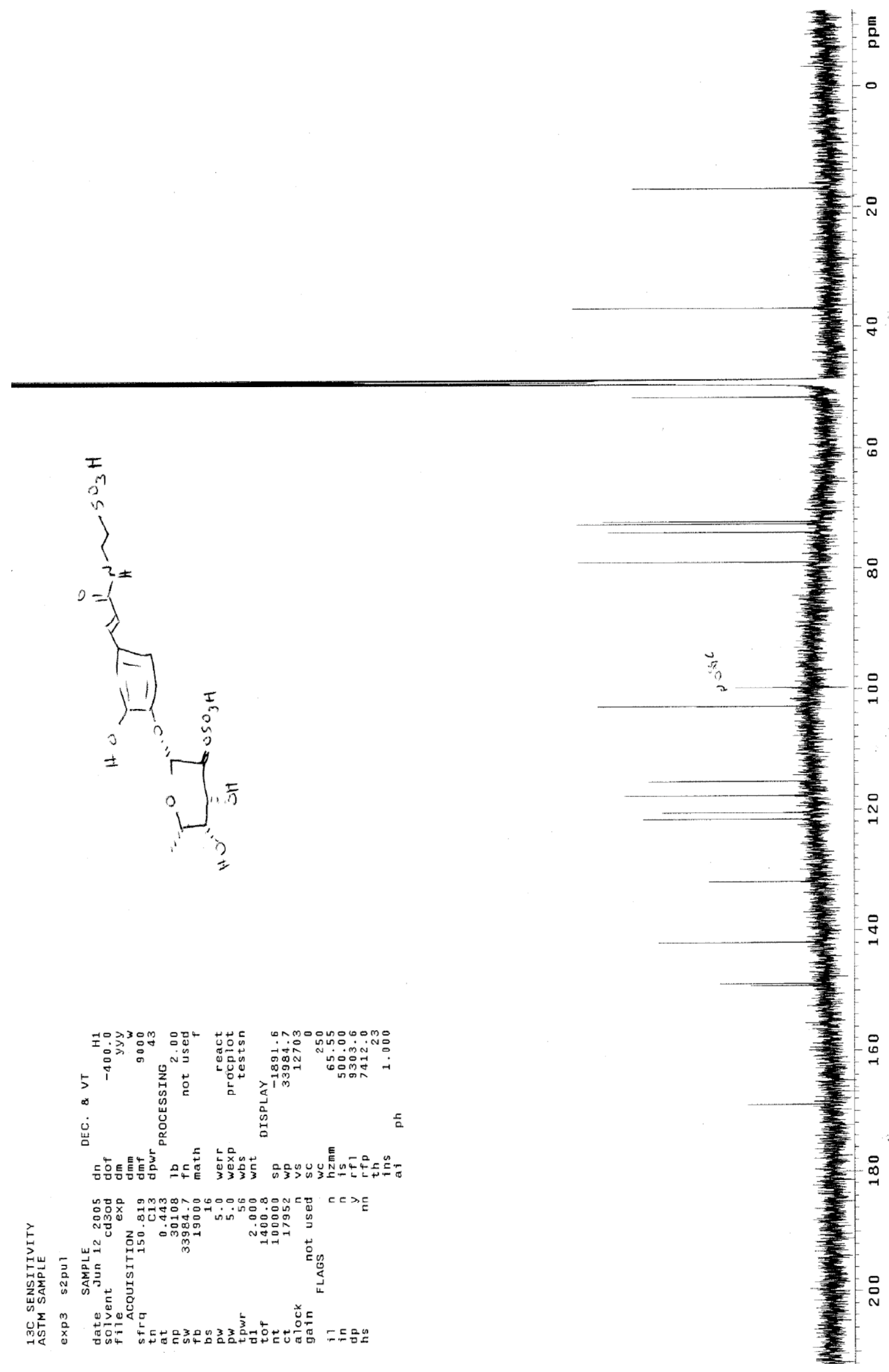

